\title{
ELABORACIÓN DE UN VOCABULARIO DE ESPECIALIDAD EL VOCABULARIO MÉDICO CON TODAS LAS VOCES RECOGIDAS EN LOS DICCIONARIOS DE USO
}

\author{
Vocabulary development of a medical specialty. Vocabulary with \\ all voices in the dictionary of use
}

\author{
Margarita Cundín Santos* \\ Roberto Olaeta Rubio**
}

\begin{abstract}
RESUMEN
En este artículo se analizan los distintos aspectos que conforman la elaboración de un vocabulario de especialidad, en concreto el Vocabulario médico. Con todas las voces recogidas en los diccionarios de uso. Asimismo se pretende dar a conocer las novedades que contiene este Vocabulario con respecto a otras obras lexicográficas, como es la selección del corpus de trabajo, la estructura de los artículos y las citas extraídas de diversos tipos de fuentes que han servido de base para la redacción de los diferentes sentidos y que complementan la información sobre la unidad léxica.

Palabras clave: macroestructura, microestructura, marcas diatécnicas, citas.
\end{abstract}

\begin{abstract}
In this article are analised different aspects that should be observed when working out an especial field vocabulary, and in this particular case the "Vocabulario médico. Con todas las voces recogidas en los diccionario de uso" (Medical vocabulary. With all the words gathered from particular dictionaries). At the same time we try to present the novelties that appear in this "Vocabulario" in relation to other lexicographic works as it is the selection of the corpus of this words, the structure of the articles and the quotations extracted from different kind of sources that were taken as a base for the redaction of the different meanings that complement the information of the lexical unit.
\end{abstract}

Key Words: macrostructure, microstructure, diathenical marks, quotations. 


\section{Introducción}

Vista la significativa evolución que la medicina ha experimentado en las últimas décadas y el ingente número de espacios destinados a la divulgación de temas relacionados con este campo científico, donde cada día es mayor la presencia de términos que designan nuevas enfermedades, múltiples tratamientos farmacológicos, técnicas diagnósticas cada vez más sofisticadas, etc., se planteó la necesidad de confeccionar un nuevo modelo de obra lexicográfica que ayudara al público no especialista a entender la terminología propia del ámbito de la medicina y las ciencias de la salud. La finalidad de la obra es completar y enriquecer los conocimientos de los pacientes y de sus familiares y solventar sus dudas acerca del sentido de algunos términos sin necesidad de acudir a otras fuentes. Y, quizá, de manera un tanto inconsciente, nos embarcamos en una tarea ardua, no exenta de obstáculos, pero con la ilusión de redactar una obra práctica, manejable y útil para el público en general y con el valor de enfrentarse con los problemas que irían surgiendo en el devenir de la redacción y el afán de buscarles solución.

Tras casi cuatro años de duro trabajo, por fin, vio la luz el Vocabulario médico. Con todas las voces recogidas en los diccionarios de uso. El interés de la obra es innegable si se considera la relevancia que tiene su objeto de estudio desde distintos puntos de vista. En primer lugar, la obra tiene importancia en sí misma, pues se trata del primer vocabulario que recoge las voces y usos propios de la medicina contenidos en los diccionarios generales de lengua, lo que la hace una herramienta útil para el estudio de este tipo de léxico. Por otro lado, es evidente la necesidad de este tipo de obras, pues su publicación supone la presencia en el mercado de un nuevo modelo de vocabularios, los terminológicos destinados a usuarios no especialistas en la materia.

En este trabajo se pretende dar a conocer las novedades que contiene este Vocabulario con respecto a otras obras lexicográficas, para ello se tendrán en cuenta los siguientes aspectos:
1 corpus de trabajo; 2 tipos de entradas; 3 estructura de los artículos.

\section{Corpus de trabajo}

El primer problema que encontramos fue determinar qué voces debían conformar la macroestructura o lemario del Vocabulario para tratar de compensar o de paliar las carencias, por parte del público en general, del vocabulario especializado. Así, pues, después de estudiar varios tipos de obras (bases de datos terminológicos, enciclopedias médicas y diccionarios enciclopédicos, diccionarios especializados, etc.) y visto el perfil de los destinatarios del trabajo, pacientes con escaso dominio del vocabulario médico a los que se pretende proporcionar una descripción terminológica médica básica, la selección de los lemas se restringió a la marca «medicina» en algunos de los diccionarios generales de la lengua, de uso más frecuente entre los hablantes de español, como son: Diccionario del español actual, en adelante DEA; Diccionario de uso del español, en adelante DUE; Diccionario usual de la lengua española, en adelante DRAE01; Diccionario de uso del español de América y España, en adelante vox; Diccionario Salamanca de la lengua española, en adelante DSLE; Clave. Diccionario de uso del español actual, en adelante ClAVE. M. ${ }^{\text {a }}$ Teresa Cabré (1993: 273-4) destaca que los diccionarios, vocabularios y demás trabajos léxicos y las bases de datos terminológicos son las fuentes de consulta habitual de los terminógrafos.

Este criterio para configurar el corpus del trabajo proporciona una amplia visión de las voces con marca «medicina» en los diccionarios de uso del español actual, pero se presentan otros inconvenientes, como por ejemplo: a) no figuran algunos tecnicismos presentes en el léxico general y que los diccionaristas los lematizan sin marca; b) no se incluyen todas las entradas pertenecientes a los diferentes ámbitos de la medicina, como pueden ser anatomía, psicología, fisiología, cirugía, etc., puesto que si no se etiqueta una entrada o una acepción con la 
abreviatura Med., esta no se ajustará al criterio de selección de voces $\mathrm{y}$, por consiguiente, no formará parte del estudio; c) no figuran todos los lemas con la marca Med., debido, principalmente, a que la elaboración de una obra de este tipo, por sus propias características, se presta a los más variados errores (en el Apéndice I se recogen las voces marcadas diatécnicamente y que no se detectaron), pues no podemos obviar las limitaciones y deficiencias que se derivan de un trabajo de este tipo llevado a cabo por dos personas.

\section{Tipos de entradas}

Las entradas del Vocabulario son de dos tipos. Por un lado, los artículos lexicográficos, en que al encabezamiento en negrita sigue toda la información relativa a esa unidad léxica, y por otro lado las remisiones, en que el encabezamiento va seguido de una palabra que envía al lector a esa entrada. La mayoría de las remisiones afectan a lemas que presentan variantes ortográficas, frecuentemente contiguos en el Vocabulario o que se encuentran muy próximos y no implican para el usuario un esfuerzo añadido para solventar las dudas suscitadas sobre el sentido y uso de la voz: amebiosis y amebiasis; astígmata y astigmático; pospandrial y postpandrial, son algunos ejemplos. En otras ocasiones, cuando las alternancias ortográficas afectan a la primera letra de la palabra, la distancia entre las voces relacionadas es mayor; se registran las alternancias k/qu (kinesiología o quinesiología), i/y (iatrogenia o yatrogenia), ps/s (psicosis o sicosis). Asimismo se han utilizado las remisiones en los casos de términos habituales en épocas anteriores, pero desusados en la actualidad y conocidos por otra denominación; por ejemplo alegrar, hoy desusado, remite a la voz habitual legrar; procidencia remite a prolapso. Sin embargo, en contadas ocasiones, no se ha realizado una remisión propiamente dicha, sino que se ha especificado que se trata del nombre antiguo o desusado de una determinada enfermedad, para que los usuarios que desconozcan esas voces no tengan dudas acerca de su vigencia. Por ejemplo, en el artículo tisis se lee: ' 2 Nombre con el que antiguamente se designaba a la tuberculosis pulmonar'; tínea se ha definido como: 'Antigua denominación para las infecciones de la piel producidas por hongos. Dermatofitosis, tiña'. También se ha usado este procedimiento para señalar variantes diastráticas entre los términos relacionados, como usagre: 'Nombre vulgar de la costra de leche'; rija: 'Término popular para designar la dacriocistitis', etc. Finalmente, se usan las remisiones para indicar la relación sinonímica existente entre dos voces, una más conocida entre los no especialistas en la materia y la otra común entre los profesionales de la medicina: rectitis, rectoscopia y rectoscopio remiten a proctitis, proctoscopia y proctoscopio respectivamente.

Respecto de los artículos lexicográficos, cada uno de ellos está dedicado a una unidad léxica simple, a excepción de algunos nombres y locuciones en lengua extranjera, adoptados por el uso español. Se trata de los sintagmas angor pectoris, cor pulmonale, delirium trémens, in utero, manu longa, noli me tangere y post partum colocados en el lugar alfabético correspondiente.

Las locuciones o términos compuestos, formados por varias palabras, se explican dentro de la entrada correspondiente a una de esas palabras. En general, se ha tenido en cuenta el conjunto léxico, pero la macroestructura la constituye el núcleo de la unidad, generalmente el sustantivo y el modificador aparece como subentrada. Aun así, no todas las unidades sintagmáticas deberían ser tratadas de la misma manera, porque todas no son iguales: unas son más propensas a figurar como subentradas porque el núcleo de ese sintagma se constituye en hiperónimo de la unidad, de manera que se puede afirmar que acromatopsia parcial es un tipo de acromatopsia, anticuerpo monoclonal un tipo de anticuerpo, etc., por eso parece lógico que se incluyan en los diccionarios en el lugar correspondiente al sustantivo. Sin embargo, el comportamiento de otras lexías compuestas es diferente, ya que los conceptos unidos en el sintagma no pertenecen al mismo campo semántico que el del hiperónimo. Por ejemplo: 
agua angélica, se trata de una bebida purgante, $\mathrm{y}$ no de un tipo de agua, con fórmula $\mathrm{H}_{2} \mathrm{O}$; astas de la médula o árbol respiratorio deben su nombre a una creación metafórica; ceguera verbal no está relacionada con el hecho de no ver, sino con la imposibilidad de leer; furor uterino no es un tipo de cólera o ira exaltada; moscas volantes no denota ningún insecto díptero, así como tampoco risa sardónica hace referencia a ninguna muestra de alegría, propia de la risa. Quizá hubiera sido conveniente que, en estos casos y otros similares, en lugar de figurar como subentradas de un lema considerado como núcleo, pero con el que no guarda relación semántica alguna, hubieran figurado como lexías complejas independientes. Esto no se ha realizado así para evitar una posible sensación de disparidad a la hora de validar los artículos y mantener la uniformidad de la obra (vid. Apéndice II, donde se reflejan las voces que hubieran debido figurar como entradas independientes).

En principio, en el Vocabulario se registran unidades plenas, es decir, aquellas unidades con las que nos comunicamos, pero, en contadas ocasiones, hallamos morfemas característicos del campo de la medicina. Así, se han lematizado algunos artículos que se corresponden con palabras que en su origen eran independientes y que, con el paso del tiempo, se han adaptado formalmente para funcionar como prefijos. Se trata de elementos muy productivos en el ámbito de la medicina como: apico-, cardio-, dento-, -ectomía, esfigmo-, hepato-, histo-, inmuno-, muсо-, neuro-, otoy -terapia. A este respecto, puede parecer que solo deberían figurar aquellas unidades que empleamos en los actos de habla y no los morfemas, pero eso supone un aumento considerable del número de entradas y de ahí que los diccionaristas opten por validar elementos formativos valiéndose de la competencia del hablante. Estos artículos se han consignado como 'raíz prefija' o 'raíz sufija'. En las entradas de una raíz prefija o sufija se ofrece la información sobre su significado y la cita final sirve, no sólo para corroborar este significado, sino que también muestra la capacidad productiva de ese elemento compositivo (vid. apico en Olaeta y Cundín 2011: 57).

Respecto de las voces homógrafas, se han lematizado en artículos separados el nombre femenino que designa una rama concreta de la medicina y el adjetivo y nombre referido a esa ciencia y a las personas que la cultivan. Así, se ha lematizado farmacodinámica por un lado, y por otro, farmacodinámico -ca. Esta decisión se debe a criterios de uniformidad, pues en los términos que presentan diferencia de lexema o de sufijo la separación de entradas es incuestionable: hepatología, hepatológico -ca y hepatólogo - ga, son algunos ejemplos.

No se ha tenido en cuenta el criterio etimológico para separar artículos homónimos de origen distinto (enema de enĕma 'lavativa' y enema de enhaemon 'remedio para cortar la sangre'), pues en la actualidad, la mayoría de los usuarios de diccionarios desconocen la procedencia de las entradas, por ello las palabras homónimas se han incluido como acepciones distintas dentro de un mismo artículo, así se ha eludido el problema de la homonimia y de las voces con diversos sentidos que figuran en este Vocabulario, pues no es clara en todos los casos la frontera entre la homonimia y la polisemia, proporcionando, de esta manera, sistematicidad a la obra y evitando caer en posibles incongruencias. Se ha establecido, asimismo, una sola entrada cuando se ha producido el fenómeno de la traslación o transposición, es decir, cuando una voz perteneciente a la categoría gramatical de adjetivo pasa a la de sustantivo o viceversa. Los ejemplos son numerosos: abstergente, acneico, béquico, cancerígeno... Sin embargo, no se ha tenido en cuenta esta consideración en el caso de que los términos homónimos pertenezcan a categorías gramaticales dispares, como es el caso de fistular, adjetivo en unos contextos ('de la fístula') y verbo en otros ('hacer que una llaga se convierta en fístula').

No se han lematizado nombres propios, excepto cuando están lexicalizados o forman parte de un nombre compuesto (síndrome de Down, enfermedad de Addison). El sistema de 
validación de epónimos en los diccionarios lingüísticos ha provocado que algunas de estas entradas figuren dos veces. Habitualmente, los diccionarios lematizan, por un lado, el nombre lexicalizado en minúscula (párkinson, alzheimer) y, por otro, la unidad sintagmática que se incluye como subentrada de un hiperónimo, generalmente, enfermedad o mal.

Las marcas comerciales son escasas en esta obra, únicamente se incluyen algunos nombres de medicamentos cuya definición viene encabezada con el sintagma 'nombre comercial'. Son los casos de aspirina, aureomicina, neosalvarsán, novocaína y salvarsán. Asimismo se encuentran en el Vocabulario nombres de fármacos sedantes, estimulantes, relajantes, analgésicos, antipiréticos, diuréticos, antibióticos, etc. (bencedrina, benzodiacepina, aminofilina, aminopirina, dapsona, etc.) definidos como 'medicamento' o 'antibiótico' seguidos del adjetivo correspondiente a la acción que dicha sustancia ejerza en el organismo. En ningún caso la definición de los fármacos figura encabezada por el principio activo ya que estos no constituyen una entrada principal y se decidió que todos términos que conformaran las definiciones debían formar parte del lemario.

\section{Estructura de los artículos}

Como es bien conocido, en la estructura básica del artículo lexicográfico debe figurar una entrada y la información que se facilita sobre ella. Los lexicógrafos (Rey-Debove, 1971a; Ahumada, 1989; Haensch et al., 1982) aducen que la estructura básica de un diccionario debe construirse en torno a tres aspectos: se ha de facilitar información sobre la forma de la unidad léxica (forma del signo, es decir la entrada), sobre el funcionamiento de esa unidad (información gramatical acerca de la categoría) y sobre el significado (información semántica).

Siguiendo este esquema, en esta obra figuran, en primer lugar, aspectos que atañen a la forma de la entrada. En este sentido se ha optado por incluir datos relacionados con las variantes gráficas $\mathrm{y}$, en los casos necesarios, indicaciones ortográficas. Sin embargo, no se ha considerado oportuno proporcionar datos relativos a la etimología de la entrada, a su pronunciación, a la vigencia del término, etc. El segundo bloque informativo da cuenta de la categoría gramatical de la entrada; a continuación, se ofrece información sobre el significado, es decir, las distintas acepciones que conforman la definición. En línea aparte, se aportan las citas extraídas de diversos tipos de fuentes, que han servido de base para la redacción de los diferentes sentidos y que además complementan la información sobre la unidad léxica y transmiten datos imprescindibles sobre el sentido del término y sobre la combinación de los elementos en los textos reales, lo cual proporciona una valiosa ayuda al usuario no sólo en la comprensión del término, sino también en la producción de mensajes.

\subsection{Macroestructura}

Respecto de la macroestructura, se incluye siempre en negrita, en minúscula (a excepción de las siglas) y en tamaño mayor de letra que el cuerpo del artículo. La elección de la forma más ortodoxa de la entrada se ha regido por una serie de criterios de acuerdo con la categoría gramatical a la que pertenezca:

a) Los sustantivos, según el género que posean, aparecen representados por la forma masculina singular (abrebocas m.) o femenina singular (abdominalgia $f$.), y, si presentan variación genérica por la forma del masculino y femenino singular, simplificando esta última a su terminación (andrólogo, ga). En el caso de sustantivos que solo se utilizan en plural, la forma canónica será obviamente la del plural (acores m. pl.; adenoides $f$. pl.; constantes vitales $f$. $p l$.).

En algunas ocasiones, puede dar la sensación de que se ha producido la doble validación de un término, puesto que se han registrado, en distintos artículos, dos variantes gráficas de la misma 
enfermedad cuya única diferencia es la presencia o ausencia de la -s final (herpe y herpes; lúe y lúes; sanie y sanies; tétano y tétanos). Ello se debe a la falta de unanimidad para validar estas voces a lo largo de la historia.

b) Los adjetivos se validan mediante su forma singular. En los de dos terminaciones se incluye el masculino acompañado del femenino. En el caso de que un adjetivo sea invariable, no se especifica (antipolio).

c) Los verbos se catalogan por la forma del infinitivo.

d) $\mathrm{Si}$ se trata de formaciones compuestas o locuciones tomadas de una lengua extranjera, el artículo lo constituye el nombre o la locución entera (angor pectoris, cor pulmonale, delirium trémens, in utero, manu longa, noli me tangere, post partum).

e) En el Vocabulario tienen cabida algunos adverbios terminados en mente, procedentes del DEA, pues según sus autores, aunque es frecuente su exclusión en los diccionarios españoles porque son tantos como los adjetivos sobre los que se forman y su significado se desprende de los mismos adjetivos, el uso acepta unos y rechaza otros. Por consiguiente incluyen todos los adverbios de esta clase, tanto si su significado es el propio del adjetivo primitivo, como si han desarrollado otro cuyo uso se ha comprobado. Estos adverbios se han suprimido en la edición del DEA 2011.

En cuanto a las variantes gráficas, ocasionalmente, se ha añadido, tras el lema, entre paréntesis, información de carácter ortográfico, que se cataloga en tamaño menor de letra e incluye las variantes ortográficas aceptadas en el uso general, por lo que ocupan la misma posición en la macroestructura: anafrodisíaco, ca (o anafrodisiaco); aréola (o areola), etc. Sin embargo, otras variantes no se han consignado en la misma posición en la macroestructura, sino que se han registrado en el lugar correspondiente de acuerdo con el orden alfabético y su único definidor es una remisión a la variante más usada (kinesiología, quinesiología; psicopatía, sicopatía, etc.).

Se han unificado los criterios de validación de los lemas con doble acentuación. En la mayor parte de los casos se ha optado por incluir en primer lugar la forma preferida por los especialistas de la medicina, haciendo concesión a las formas etimológicas, es decir, se prefiere la terminación -íaco a-iaco.

No se aplica la dualidad acentual a todas las palabras que terminan en -ía/-ia. La pronunciación de estas vocales en final de palabra es muy vacilante, debido a que se trata de vocablos de origen griego muchos de los cuales llegaron al castellano a través del latín, por lo que unas veces se ha mantenido la acentuación griega (con hiato) y otras la latina (con diptongo). Así se han incluido hemiplejía (o hemiplejia), paraplejía (o paraplejia); pero solo apoplejía pues la forma diptongada no se incluye en ningún diccionario.

Por otro lado, se ha añadido una variante para la erupción cutánea, recogida solo en DEA con la grafía histrix. Ha sido imposible documentar esta variante, pues en todas las fuentes médicas consultadas, la única forma consignada es hystrix (o menos frecuentemente ictrix). Por consiguiente, la macroestructura que se ha validado ha sido la variante recogida en DEA (histrix) y, a la misma altura, entre paréntesis, la variante más usual en los textos médicos (hystrix), por ser esta la forma que los usuarios probablemente encontrarán en las distintas fuentes.

Otras alternancias en la validación de lemas hacen referencia al uso del guion. En el caso de compuestos de dos adjetivos se observa cierta variedad. La tendencia es que cuando el primer elemento es una forma contracta del adjetivo se escriban en un solo término, pero en el uso actual se duda entre la fusión o el empleo del guion como se aprecia en los diccionarios. En el resto de compuestos se observa una clara tendencia a la fusión. En estos casos, se ha decidido 
validar ambas variantes en un mismo artículo, con preferencia por la escritura en una sola palabra: bypass (o by-pass o by pass), cowpox (o cow-pox), maxilofacial (o maxilo-facial).

Por otro lado, en las subentradas, la palabra del lema está representada por una virgulilla $(\sim)$. Si el lema es un adjetivo con variación de género, la virgulilla representa el género que corresponde al referente que se indica en la subentrada:

herida $f$. $\| \sim$ abierta Herida cuyos bordes se hallan separados. $\nVdash$ contusa Pérdida de continuidad de la piel causada por una contusión o golpe. [...].

histérico, ca adj. / m. y f. [...]Aura (o aura epiléptica) Cualquiera de las sensaciones que anuncia una crisis en alguna enfermedad.

Las locuciones adjetivas, adverbiales $y$ verbales se han validado y ordenado alfabéticamente por la forma simple del sustantivo que contienen. De esta manera, las locuciones adjetivas en sábana, de Colles, de disco, de hiato y de martillo figuran en el lugar correspondiente de las letras $S, C, D, H$ y $M$ respectivamente. Por su parte, la locución adverbial a corazón abierto se incluye en la letra $C$ y la locución verbal curar de primera intención, en la letra $I$.

\subsection{Microestructura}

Según advierten un importante número de lexicógrafos, la microestructura ha de ser constante; de ahí que en los diccionarios de lengua siempre aparezcan determinadas informaciones necesarias. No obstante, hay que hacer constar que no hay acuerdo para determinar cuáles son con exactitud dichas informaciones. ReyDebove (1967) defiende como información necesaria la categoría gramatical y el género de la voz de entrada y una definición; sin embargo, Fernández Sevilla (1974: 81 y ss.) advierte que las informaciones tienen que ser más abundantes, se debe facilitar la etimología, la pronunciación, niveles de lengua, etc. Estos autores coinciden con lo señalado por L. Zgusta (1971), por L. Collignon y M. Glatigny (1978).

El contenido de los artículos de este Vocabulario se divide en cuatro partes: información gramatical y marcas diacrónicas, información sobre el significado, cita donde se refleja el sentido del término, diccionarios de uso que compilan el término.

\subsubsection{Información gramatical}

En primer lugar se informa acerca de la categoría gramatical. Teniendo en cuenta el propósito de esta obra y las necesidades de sus futuros usuarios se ha suprimido la información sobre la etimología de las voces; sobre aspectos sintácticos, como las preposiciones con las que se construyen; sobre las irregularidades morfológicas; sobre restricciones diatópicas o restricciones de un determinado nivel o registro de la lengua, por ello no se encontrarán las marcas raro, coloquial, científico, etc.; tampoco se ha hecho alusión alguna a restricciones cronológicas, por lo que no constan las marcas antiguo, arcaico o desusado, si bien en el Vocabulario se han validado auténticos arcaísmos que hacen referencia a aparatos o instrumentos médicos obsoletos, a enfermedades inexistentes o inusuales en la actualidad, a unidades de medida o a remedios y composiciones farmacéuticas que se utilizaron en siglos precedentes, etc. Si el lema es un término que ha sido tomado de una lengua extranjera, no se indica ni la lengua de procedencia ni la pronunciación ni la formación del plural ni cualquier otra información habitual en los diccionarios generales de lengua.

Para simplificar, únicamente se indica el género de los sustantivos mediante las abreviaturas $m$. (masculino) y $f$. (femenino); y la clase de verbos, mediante las abreviaturas tr. (transitivo), intr. (intransitivo) o prnl. (pronominal). Si un sustantivo tiene variación de género se indica (andrólogo, ga $m . y$ f.). En los casos de recategorización, cuando un adjetivo ha pasado a la categoría gramatical de sustantivo o viceversa, no se han establecido subgrupos que indiquen estos cambios de sentido, ni se ha 
colocado la abreviatura correspondiente a la categoría gramatical delante de la acepción a la que hace referencia, sino que ambas categorías gramaticales se marcan inmediatamente después de la macroestructura (agnósico, ca adj. / m. y $f$; acneico, ca $a d j . ~ / m . y f$., antirreumático, ca $\operatorname{adj}$. / $m$., antiséptico, ca $a d j$. / m., etc.) indicando con ello que esos lemas, que se han definido única y exclusivamente como adjetivos, se utilizan en ocasiones como sustantivos: «antiséptico, ca adj. / $m$. \| Que impide el crecimiento y la reproducción de microbios. Aplicado generalmente a medicamento o sustancia» (Olaeta y Cundín 2011: 52).

Para denotar el género de ciertos sustantivos, no se ha añadido la voz ambiguo, como hacen algunos diccionarios, sino que se ha indicado el género más usual y entre paréntesis, precedido de la conjunción $o$, el género menos aceptado en el uso, indicando con ello, que esas voces habitualmente se usan como propias de un determinado género, pero en ocasiones también se utilizan como propias del género contrario: acné $m$. (o $f$.), herpes $m$. (o $f$.), etc. De manera similar se ha obrado con los términos que designan a las personas que ejercen ciertas profesiones, y que algunos diccionarios califican de género común (terapeuta, fisioterapeuta, homeópata, alópata). En el Vocabulario, se han colocado las abreviaturas correspondientes a los géneros masculino y femenino $(m \cdot y f$.), indicando que, según el contexto, ese término será masculino o femenino.

Consideración aparte merecen los casos de algunas locuciones verbales, adjetivas y adverbiales, así como las frases hechas. Habitualmente la abreviatura correspondiente a la categoría gramatical de la macroestructura figura junto a esta y separada de la definición propiamente dicha mediante una doble pleca. Como se ha mencionado anteriormente, esta información no se repite delante de cada sentido o de cada subentrada. Sin embargo, en ocasiones, cuando el sentido no corresponde al lema, sino a una locución o a una frase hecha de la que forma parte ese lema, ha sido necesario añadir la categoría gramatical, para evitar incongruencias entre la identidad categorial del definido y el definidor. Por eso en el artículo herida, por ejemplo, figura al principio la abreviatura correspondiente al género de esta palabra $(f$.) y no se repite tras los sublemas herida abierta, herida contusa, herida incisa, herida penetrante y herida punzante. Sin embargo, una palabra perteneciente a una determinada categoría puede formar combinaciones estables con otras palabras formando unidades que la sitúan en una categoría distinta a la suya propia, por ejemplo, manifestar la herida. En estos casos, la ausencia de información sobre la categoría gramatical de esa unidad léxica compleja no se entendería, puesto que evidenciaría la falta de identidad entre la macroestructura y la microestructura. Por consiguiente, tras el sublema, marcada en negrita, se ha colocado la abreviatura de la locución correspondiente o, en su caso, el sintagma «frase hecha» (vid. Apéndice III).

El número se ha marcado solo en el caso de aquellos sustantivos que se usan en plural (acores, adenoides, constantes vitales, longuetas, loquios, secundinas). En otros casos, se ha validado el término en singular, pero se ha añadido entre paréntesis la fórmula «frec. en plural», indicando que, en el ámbito médico, es habitual su empleo en plural (complicación, desarreglo, fomento, vaho, variz, vegetación).

\subsubsection{Información sobre el significado}

En la redacción de las acepciones, siguiendo al profesor H. Mederos (1994: 97-101), se tuvieron en consideración una serie de aspectos, como las definiciones proporcionadas en los diccionarios que han servido de base para la obtención del corpus del Vocabulario; la información obtenida en los diccionarios médicos y en libros y revistas especializados; la ordenación de las acepciones; $y$, la naturaleza de los sentidos.

Respecto al primer aspecto, se puede afirmar que los diccionarios generales de lengua son obras que se copian, la mayoría de las definiciones son prácticamente iguales: en algunos artículos, abrevian o amplían mínimamente la información incluida; en otros, 
se limitan a variar alguna palabra, pero el contenido es prácticamente idéntico. En este sentido, el DEA es el diccionario más novedoso, pues parte de fuentes de datos ad hoc, lo que le ha permitido incrementar las entradas, ampliar definiciones y disponer de ejemplos para ilustrar los artículos y mostrar las colocaciones de las unidades léxicas.

Por lo que atañe a la ordenación de los sentidos en este Vocabulario, se ha tenido en cuenta el criterio de extensión de uso, pero no siempre ha sido posible determinar si un sentido está más extendido y, por ende, es más habitual entre los hablantes que otro. En ocasiones, se ha acudido a los diccionarios especializados y otras obras de referencia para comprobar si el orden de las acepciones establecido en los diccionarios lexicográficos se ajustaba al criterio adoptado en los diccionarios especializados, y se ha podido comprobar que, en unas ocasiones, el sentido recogido en los diccionarios generales de lengua no se incluye en los diccionarios técnicos y, en otras, se incluye con restricciones cronológicas.

La naturaleza de los sentidos es el tercer aspecto que se ha tenido en cuenta para redactar una definición adecuada. Así la definición de los adjetivos relacionales o la de los adverbios terminados en -mente se ha efectuado mediante palabras de su misma familia léxica, para evitar redundancias en los artículos lexicográficos. En la definición de enfermedades, aparatos, pruebas, etc., se han tenido en cuenta algunas características que configuran su estereotipo, de manera que en el caso de unos sustantivos, lo más importante ha sido destacar su función, mientras que en el caso de otros ha primado su naturaleza. Se han evitado siempre las definiciones formuladas con las proposiciones 'cualidad de' o 'estado de', seguidas de un adjetivo de la misma familia léxica que la del definido, ya que no aclaran nada ni permiten conocer el significado. Frente al sintagma 'cualidad de mate', utilizado en la definición de matidez tanto en DEA como en DUE, en el Vocabulario se ha optado por 'sonido amortiguado a la percusión del cuerpo humano, que puede ser normal o patológico según las zonas'.
Uno de los principales inconvenientes que se ha tenido que solventar ha sido el hecho de que los términos empleados en el lenguaje médico han cambiado a lo largo del tiempo su sentido originario; sin embargo, en algunos diccionarios generales no solo sigue figurando ese sentido obsoleto, sino que incluso su orden de aparición en el artículo lexicográfico es anterior a otros sentidos que sí están vigentes. Ya Casares (1950: 70 y ss.) apuntaba que los principales criterios que se utilizan en la ordenación de acepciones se suelen denominar «empírico, genético, lógico e histórico». Un claro ejemplo lo constituye el término agenesia, cuyo primer sentido consignado en los diccionarios sin marcación cronológica alguna es 'imposibilidad o incapacidad para engendrar', relegando al segundo lugar el de 'desarrollo defectuoso o falta congénita de una estructura u órgano'. Sin embargo, en los diccionarios especializados de reciente publicación y en los textos médicos actuales nada se dice acerca de la imposibilidad para engendrar. Si se quiere encontrar documentación que corrobore este sentido hay que recurrir a textos de los siglos XVIII y XIX. En el Vocabulario se ha registrado en primer lugar el sentido vigente en la lengua actual y sólo se ha documentado este sentido (vid. agenesia en Olaeta y Cundín 2011: 14). Un proceso similar, es decir, de transferencia de sentido se observa en muchos términos procedentes de la Antigüedad clásica que hacen referencia a teorías abandonadas desde hace siglos. Algunos diccionarios generales de lengua siguen haciéndose eco del sentido primitivo de estas voces, aunque en el ámbito médico se consideren parte de la historia de la medicina y, por consiguiente, no se utilicen (términos como flemático, melancólico o atrabiliario, colérico, etc.).

Llama poderosamente la atención el sentido ambiguo que se ha dado a los términos nictalopía y nictálope a lo largo de la historia, lo que actualmente es causa de confusión entre los científicos y los diccionarios de uso reflejan esta confusión. Nictalopía lo aplican unos autores a la facultad de ver de noche o durante el crepúsculo peor de lo que lo haría una 
persona normal; pero para otros es justamente lo contrario, es decir, ver mejor de noche que de día. La Sociedad General de Oftalmología (Archivos 2002) manifiesta que nadie que actualmente lea u oiga los términos nictalopía y hemeralopía, puede saber con certeza si el autor ha querido decir una cosa o su contraria, para concluir que:

Los términos nictalopía y hemeralopía deben ser eliminados en las expresiones actuales, para evitar confusiones. Pueden ser substituidos por los sintagmas ceguera nocturna para expresar una mala visión escotópica, y ceguera diurna para una mala visión fotópica, como suele hacer la literatura científica angloamericana.

La solución adoptada en esta obra ha sido la de mostrar la ambigüedad del término y el origen de tal confusión con las citas que ilustran el uso del término:

nictálope $a d j][$ Persona] que padece nictalopía.

Archivos de la Sociedad Española de Oftalmología n. 3 2002: Hirschberg (traduce «los que sólo ven por la noche se llaman nictálopes» [nyx (noche) y álaós o álaóps (ceguera)]) ...; mientras que García Novo traduce lo mismo por «los que no ven por la noche se llaman nictálopes» [nyx (noche) y ops (visión)]) ... La disparidad de criterios se comprende si se considera que un término griego puede tener varios significados y el traductor se ve obligado a recurrir al contexto para elegir uno u otro; en este caso, Hirschberg, que era oftalmólogo, interpreta que se trata de una ceguera diurna, pues en el texto hipocrático se añade que va asociada a lagrimeo, que cura espontáneamente en días o meses y que se da en niños o en adolescentes, de lo que dedujo que se trata de una queratitis con fotofobia, y por tanto con mala visión diurna.

nictalopía $f$. $\|$ Nombre de sentido ambiguo. Ceguera nocturna o mala visión durante la noche o con poca luz o, por el contrario, facultad de ver mejor de noche que de día.

Archivos de la Sociedad Española de Oftalmología n. 3 2002: A los términos «nictalopía» $\mathrm{y}$ «hemeralopía» se les ha dado a lo largo de la historia un significado ambiguo, lo que actualmente es causa de confusión entre los científicos. Nictalopía lo aplican unos autores a la facultad de ver de noche o durante el crepúsculo peor de lo que lo haría una persona normal; pero para otros es justamente lo contrario, es decir, ver mejor de noche que de día. Hemeralopía se ha usado para expresar la facultad de ver bien de día (y por extensión, mal en el crepúsculo y noche); pero también se le ha dado el significado contrario, es decir, el de ver peor de día que de noche.

Debido a procesos polisémicos y de extensión de significado, en ocasiones ha sido necesario completar la microestructura de un artículo con una acepción nueva que no figura en ninguno de los diccionarios generales de lengua, pero que es de uso generalizado en los textos científicos médicos. En efecto, algunos términos han perdido su primitivo sentido y han adquirido otro sentido técnico. Por consiguiente, la redacción de la definición se ha llevado a cabo partiendo de los contextos a la hora de informar sobre el lema (teoría operacional o contextual), pues el sentido de un término emana de su uso, y a continuación se ha formulado el sentido o sentidos identificados (fase referencial). (Vid. Apéndice IV).

Por ejemplo, el sentido que ofrecen los diccionarios generales de la lengua del término explantar pertenece al campo científico de la Biología, a pesar de figurar con la etiqueta $\mathrm{Med}$. en DEA: 'Trasladar [tejidos vivos] de su lugar natural a un medio de cultivo'. La mayoría de las referencias tanto en periódicos, como en las revistas y los manuales de medicina no registran ese sentido, sino el que se señala en esta obra en la primera acepción:

explantar $t r \|$ Extraer un órgano o un implante. \| 2 Transferir un tejido vivo del cuerpo a un medio de cultivo.

El Mundo 02.08.00: Las mujeres portadoras de prótesis de soja que hayan sido llamadas o que acudan voluntariamente a un cirujano para ser informadas recibirán, en primer lugar, un folleto sobre las prótesis mamarias 'Trilucent', así como datos sobre las razones que han llevado a recomendar la explantación de las prótesis, «haciendo especial hincapié en el carácter de precaución que tiene esta recomendación». ... Según el protocolo, al explantar la prótesis, el cirujano deberá tomar una muestra del tejido 
circundante que forma la cápsula, para remitir al laboratorio una cantidad de muestra suficiente para su examen anatomopatológico.

Debido a la frecuencia de aparición de términos sinónimos en el lenguaje médico y con el fin de evitar la repetición del contenido de la microestructura y aumentar el volumen de la obra se han empleado remisiones. De esta forma, la inflamación de la mucosa rectal puede decirse proctitis y rectitis; la intervención quirúrgica para restaurar partes dañadas del organismo con injertos del propio paciente, anaplastia o autoplastia; el estado de profunda desnutrición y deterioro observado en la fase final de algunas enfermedades cacoquimia y caquexia; etc. En ocasiones, la vinculación entre las voces refleja registros de habla, es decir, términos vivos en el habla cotidiana, conocidos popularmente, y términos ultraespecializados, de uso exclusivo entre profesionales (hormigueo y mirmestesia).

Por el contrario, algunos términos suelen ser considerados sinónimos estrictos, pero son realmente parónimos. Por ejemplo, no se ha realizado remisión entre asfixia y apnea puesto que el primero se emplea en el sentido de supresión de la función respiratoria y el segundo, casi siempre en el de suspensión transitoria de dicha función a continuación de una respiración forzada; algo similar ocurre con los términos cáncer y neoplasia, que, por lo general, son considerados sinónimos, pero el primero designa las tumoraciones malignas en general, especialmente las formadas por células epiteliales, y el segundo, la formación de tejidos nuevos de carácter tumoral maligno, por ello cada término figura con su sentido específico.

Aunque se ha procurado codificar los sentidos de los términos con palabras sencillas, claras y precisas, no se ha podido evitar el empleo de nomenclaturas normalizadas, es decir, de términos aprobados por una comunidad científica concreta según unas normas que determinan su relación con los sentidos. Entre las nomenclaturas científicas que se utilizan en medicina destacan la química, la botánica, la zoología, la bacteriología, la inmunología, la botánica, etc. Anotemos, como ejemplo que aspergilosis incluye entre sus definidores el género de hongo que produce la infección; actinomicina el género de bacterias de donde se obtiene el mencionado antibiótico; tétanos el bacilo que causa esta enfermedad infecciosa.

Por otra parte, ha sido necesario incluir en algunas definiciones breves explicaciones de algunos de sus definidores. En efecto, en ocasiones, para definir un lema se hace necesario emplear una palabra que no está incluida en el conjunto de artículos que constituye el lemario de este Vocabulario, bien porque los diccionarios de uso no la marcan o bien porque la marcan con una etiqueta diferente a la de medicina, lo que obliga a desecharlo como lema entrante en esta obra. En estos casos, para no caer en definiciones insuficientes o incompletas, la solución ha sido añadir entre paréntesis y con doble pleca una breve explicación del sentido de la palabra en cuestión, para que su falta en el conjunto de lemas no suponga ningún problema de incomprensión del término que se está definiendo. Por ejemplo, en la entrada palo se ofrece una breve explicación de quina: «palo $m$. \|Nombre antiguo de la quina (\|planta originaria de América del Sur con propiedades curativas)» (vid. Apéndice V).

No se puede dejar de mencionar que, en el estudio de la terminología médica, se aprecia en los diccionarios generales de lengua la existencia de definiciones imprecisas, erróneas o inexactas, pues el contenido semántico de algunas entradas no se ajusta al sentido real de esa voz. Por ejemplo, en DUE se confunde ceromático con ceromiel o colporragia con colporrea; en DRAE no se especifica que el clavo pasado es un tumor que afecta a las caballerías, no a los humanos; en DSLE la definición de acetonemia corresponde a acetonuria; la definición que facilita el DRAE de autismo es inadecuada, y de hecho la RAE ha reconocido la imprecisión de la definición y ha anunciado que la modificará en la edición de 2014. Según la revista Ser padres, la RAE cambiará la definición actual por 'trastorno del desarrollo que afecta a la comunicación y a la interacción social, caracterizado por patrones de comportamiento restringidos, repetitivos y estereotipados'; el sentido que otorgan los diccionarios al adjetivo crioprotector no es el 
que se le otorga en el ámbito médico; en DEA se identifica curieterapia, radiumterapia y radioterapia. Radiumterapia y radioterapia son denominaciones alternativas, una más culta que la otra, pero no se pueden identificar con curieterapia. También se identifica en los diccionarios alcoholismo con dipsomanía, solo DEA da cuenta del matiz que diferencia ambos términos. Tampoco parece adecuada la definición del término docimasiología facilitada en DUE NI LA DEL ADJETIVO drástico que figura en DEA, DUE Y VOX. CON LA INFORMACIÓN FACILITADA DEL SUSTANTIVO noxa en DEA, DUE Y DRAE DIFÍCILMENTE SE PUEDE ENTENDER EL ALCANCE DEL TÉRMINO, ETC.

EN CUANTO A LOS MODELOS DE DEFINICIÓN, ES NECESARIO PRECISAR QUE Un vocabulario de términos médicos, dirigido a un público no especialista en la materia debe contemplar una serie de características que no se perfilan en los diccionarios generales de lengua, donde los definidores intentan mostrar el sentido o los sentidos de la palabra definida consolidados por el uso, sin abundar en explicaciones que indiquen cómo y para qué se emplea esa macroestructura. Sin embargo, no se puede negar la labor didáctica que implica el Vocabulario de términos médicos, donde no se pueden evitar duplicaciones de términos (el término duramadre se repite, puesto que se encuentra entre los definidores de epidural y extradural), desdoblamientos sinonímicos o definiciones de corte enciclopédico. Muchos autores argumentan que la inclusión de datos enciclopédicos propicia la no sujeción a la ley de la sinonimia, pero, de acuerdo con el profesor H. Hernández (1994: 65): «estimamos que el principio en cuestión no debería regir para este tipo de definiciones. El lexicógrafo [...] deberá decidir sobre el mayor o menor contenido enciclopédico del diccionario que va a elaborar de acuerdo con su finalidad y el tipo de usuarios a quien se destina». Al hilo de esta cuestión, H. Hernández (1994: 65-6) considera imprescindible tener en cuenta una serie de principios para redactar las definiciones, como son: evitar la información hiperespecífica; controlar la presencia de nombres propios; admitir que el lexicógrafo actúa como mediador entre la sociedad y su lengua, etc.

Se ha seguido un modelo de definición formulado en la metalengua del contenido, es decir se han redactado definiciones propias o parafrásticas (Bosque 1982: 107-8), que son conceptuales (Fernández Sevilla 1974: 69). En un considerable número de artículos, el modelo de definición empleado ha sido el hiperonímico, aunque no faltan algunas definiciones antonímicas: afebril, asintomático (ReyDebove 1970: 3-34) o de componente negativo: avitamínico, avitaminosis o carencia ni tampoco sinonímicas: manu longa.

Se han evitado las definiciones que comienzan con la fórmula 'acción y efecto de' o 'acción y resultado de', pues se ha considerado que no ayudan a conocer el sentido del término, sino que nos remiten a otra, en este caso el verbo correspondiente. Según L. Castro (1996: 1220): «Se trata de una tarea urgente que hay que realizar en un diccionario para separar aquello que puede ser explicado sólo como derivado, de aquello que exige una definición que rompa con una remisión directa al verbo, y dando cuenta de un amplio número de circunstancias [...]».

Para evitar las definiciones impropias y aminorar los problemas que conlleva la inclusión de información contextual, se ha separado lo propiamente definitorio del contorno de la definición, por medio de diversos procedimientos. Se han usado los corchetes para incluir en ellos los sustantivos a los que se refieren esos adjetivos. En otros casos, se indica esta información tras la definición propiamente dicha, mediante la fórmula «Aplicado generalmente a...» seguido del sustantivo al que hace referencia, proporcionando la información contextual precisa y tratando de evitar las definiciones impropias que se formarían al no existir identidad funcional ni categorial entre el definidor y el definido.

En estos casos los corchetes sirven para acotar los elementos que se encontrarán habitualmente en el uso de la palabra definida. Esta delimitación del contorno solo se ha utilizado en la definición de los adjetivos, pues se ha considerado que los usuarios de este 
Vocabulario no entenderían el porqué de la inclusión de los sujetos o los complementos de los verbos entre corchetes, antilambdas o cualquier otro elemento tipográfico. No se puede olvidar que no siempre es tarea sencilla separar con nitidez lo propiamente definitorio del contorno de la definición y que las definiciones redactadas mediante acumulación de sinónimos o perífrasis o ambas cosas, difícilmente se someterán a la prueba de sustituibilidad. Esta prueba se produce cuando el enunciado definidor puede remplazar al definido sin que el sentido objetivo de este se altere (Seco 1987a: 21). En los diccionarios encontramos muchos casos en los que esta prueba no se cumple, por ello algunos diccionaristas afirman que este principio no constituye una prueba indispensable para determinar la validez de una definición (Porto Dapena 2002: 273). En Vocabulario no se ha considerado realmente importante superar esta prueba para determinar la idoneidad de una definición, pues un vocabulario de un ámbito especializado dirigido a usuarios no especialistas en la materia debe regirse por otros principios.

Como se ha mencionado unas líneas más arriba, no se ha evitado las definiciones de corte enciclopédico, pues ha sido necesario no solo definir el término, sino también describir el objeto o la enfermedad correspondiente para establecer las diferencias con respecto a otros objetos o enfermedades. Por consiguiente, en el Vocabulario se ha dejado de lado la distinción tan rígida efectuada por algunos diccionaristas entre definición lexicográfica y definición enciclopédica, pues por las propias características de la obra, ambos tipos de definición deben complementarse para plasmar el significado de la mejor manera posible con las implicaciones que esto conlleva, es decir, no solo se da cuenta de la pertenencia de ese término a un área de especialidad, sino también se aportan datos sobre las relaciones de ese término con otros cercanos a él. Por ejemplo, algalia se podría haber definido como 'sonda uretral hueca' o nodación como 'dificultad para el movimiento', pero se ha querido especificar, en el primer caso, su utilidad para que no se confunda con otros tipos de sonda o de catéter y, en el segundo, la causa que impide el movimiento; así en el Vocabulario se aduce de algalia 'sonda uretral hueca empleada en las operaciones de la vejiga, para la dilatación de la uretra, y especialmente para dar salida a la orina'; y de nodación 'Dificultad o impedimento para el movimiento de una articulación por la presencia de un nódulo o pequeño tumor formado sobre los tendones o músculos'.

\subsection{Citas}

Mención especial merecen las citas por constituir uno de los elementos más importantes de la obra. Las citas se incluyen tras la relación de acepciones y subacepciones, en párrafo aparte y en tamaño menor de letra.

Entre los objetivos fundamentales de esta obra está el de completar y enriquecer los conocimientos de los pacientes y del público en general y solventar sus dudas sobre el sentido de algunas voces para que puedan entenderlas y usarlas con absoluta propiedad. Para que estos objetivos se cumplan se ha utilizado un recurso de la tradición lexicográfica española: los usos autorizados en documentos especializados. En esta obra el cometido de las citas es múltiple. Por un lado, se han utilizado como textos que se alegan como apoyo de lo que se dice; pero, al mismo tiempo, también desempeñan un papel didáctico $\mathrm{y}$, por consiguiente, añaden nueva información sobre el sentido del lema; asimismo señalan distintos registros de uso; $\mathrm{y}$, muestran los términos en su contexto de uso habitual. Por tanto, la citas no son una alternativa sino un complemento de la definición, en palabras del profesor Seco (1987b: 233) una «explicación bidimensional» del sentido. Por otro lado, Ullmann (1978: 73-4) destaca el papel de las citas y habla de la teoría operacional o contextual del significado por la que «podemos establecer el significado de una palabra observando su uso». Los ejemplos son, pues, representantes del uso del lema, por eso, en esta obra no tienen cabida los ejemplos inventados porque no pertenecen a un uso lingüístico real. En el Vocabulario, los ejemplos tienen dos cometidos: en ocasiones, se han tomado como un complemento del artículo 
lexicográfico, y otras veces, siguiendo a Landau (1984: 166) y Drysdale (1987: 213), han supuesto el punto de partida de la definición.

En el Vocabulario no se ha querido renunciar a un cierto grado de hibridismo entre los diccionarios terminológicos o especializados y los diccionarios lingüísticos. $\mathrm{Y}$ es en este sentido donde adquieren una importancia considerable los ejemplos. Mientras que el contenido de la definición se acerca a un diccionario de lengua, en los ejemplos ha primado la función definitoria y se observa la presencia de informaciones enciclopédicas y de datos culturales y sociales que completan la definición y que, en cierta manera, encierran una definición disfrazada. Por ejemplo:

estafilococia. $f$. ||Infección causada por la bacteria Staphylococcus aureus que se encuentra comúnmente en la piel humana.

VV.AA. Gestión, aprovisionamiento y cocina en la unidad familiar de personas dependientes 2008, 241: Estafilococia. La produce el Staphylococcus aureus que se encuentra de forma natural en la piel, nariz, boca y manos. Son focos de infección los cortes en las manos, heridas infectadas y flemones. Crecen rápidamente en la leche, quesos frescos, salsas y productos con nata, crema, natillas y carnes. La bacteria se destruye con el calor y sus toxinas a $100^{\circ} \mathrm{C}$ durante 30 minutos. Los síntomas se presentan entre 2 a 6 horas, con vómitos, diarreas y espasmos intestinales, a veces escalofríos y mareos.

No se puede negar, pues, el papel tan importante que desempeñan los ejemplos, pues ayudan al usuario tanto en la comprensión como en la producción de mensajes. Sin perder de vista estas funciones de los ejemplos, no resultó tarea baladí la selección de criterios para la obtención de ejemplos, de ahí que la procedencia de las citas sea tan variada, pues si bien es cierto que existe una vasta bibliografía para cada uno de los ámbitos de la medicina, también lo es que en el momento de valorar la adecuación de las citas se ha tenido en cuenta las funciones que se pretendían cubrir con los ejemplos, por eso unas veces se ha optado por insertar ejemplos procedentes de publicaciones correspondientes al ámbito de la especialidad y en otras ocasiones se ha acudido a publicaciones de carácter más general. (Vid. Rondeau 1983).

El punto de partida para la inserción de citas ha sido que estas sirvan para ayudar a entender el sentido del lema, pero también se han utilizado para añadir información nueva o para reforzar algún aspecto que se ha considerado importante y que no se refleja en la definición. En este sentido, se ha buscado presentar la información de una manera diferente y acercar los términos a su contexto de uso, para facilitar a los usuarios la comprensión. De ahí que una parte importante del trabajo se haya dedicado a la búsqueda y selección de fragmentos en los que las voces están usadas con «la mayor propiedad» y donde se explique con meridiana claridad el sentido del definido ( $v i d$. a modo de ejemplo el Apéndice VI).

Para alcanzar este propósito se ha utilizado todo tipo de fuentes documentales, desde libros, diccionarios, revistas especializadas, enciclopedias, prensa generalista, obras literarias, páginas webs, etc. Elegir la fuente adecuada para que las citas cumplan los fines mencionados ha sido una ardua tarea. Resulta relativamente sencillo encontrar fuentes donde aparezcan los términos en un contexto real; lo que no resulta tan sencillo es encontrar el contexto apropiado donde se refleje el sentido del definido de manera clara, facilitando la información que se quiere transmitir en la definición y ayudando a su comprensión. Esta dificultad aumenta en el caso de términos en claro retroceso, desusados, como es el caso de catoptroscopia, abirritar, epacmo, ceromático, carrilete (aunque los diccionarios recogen carrilete, debería figurar carrelet, voz recogida en Hurtado de Mendoza (1840) 'aguja recta de dos a tres pulgadas de largo, con la punta triangular de la que usaban los antiguos en diversas oparaciones'), cerasiote o docimasiología. Aunque se ha desechado como fuente de documentación cualquier obra de carácter lexicográfico, los términos mencionados solo se han podido documentar acudiendo a definiciones, pues solo figuran en diccionarios o en algunos sitios web pertenecientes, sobre todo, a laboratorios que incluyen glosarios de términos usados en medicina y donde se ofrece una definición escueta, como: 
TABLA 1

Documentación de arcaísmos

\begin{tabular}{|c|c|}
\hline Artículo lexicográfico & Cita \\
\hline $\begin{array}{l}\text { catoptroscopia } f \mid \text { Exploración del } \\
\text { organismo por medio de espejos. }\end{array}$ & $\begin{array}{l}\text { SaludBio Catoptroscopia. Definición: Reconocimiento del cuerpo humano por medio } \\
\text { de aparatos catóptricos (es decir, espejos o similares). (A partir de kátoptron, espejo). }\end{array}$ \\
\hline $\begin{array}{l}\text { abirritar } t \text { MAitigar o contrarrestar } \\
\text { la irritación. }\end{array}$ & $\begin{array}{l}\text { R. J. Domínguez, Diccionario nacional 1849, 5: abirritar. Med. Disminuir la } \\
\text { irritación. Quitar la sensibilidad orgánica de una parte del cuerpo sobreexcitada por } \\
\text { la enfermedad. }\end{array}$ \\
\hline $\begin{array}{l}\text { epacmo } \quad(\text { desusado }) \\
\text { |Crisis o punto culminante de la } \\
\text { enfermedad. }\end{array}$ & $\begin{array}{l}\text { W. A. N. Dorland Diccionario enciclopédico ilustrado de medicina 2005, 648: epacmo } \\
\text { (epacme) [Del gr. epakmazein, llegar al punto culminante] En la evolución, estadio o } \\
\text { período del desarrollo. }\end{array}$ \\
\hline $\begin{array}{l}\text { ceromático, ca adj } j[\text { Ungüento] en } \\
\text { cuya composición entran la cera } \\
\text { y el aceite. }\end{array}$ & $\begin{array}{l}\text { M. Hurtado de Mendoza Vocabulario Médico-quirúrgico o Diccionario de Medicina } \\
\text { y Cirugía 1840, 193: CEROMA [lat. ceroma; ceromaticus }>\text { ceromático] Nombre que } \\
\text { se aplicaba antiguamente a una especie de ungüento con que se frotaban los atletas. }\end{array}$ \\
\hline
\end{tabular}

Otro aspecto importante que hubo que abordar fue determinar el número adecuado de citas que debía consignarse en cada artículo y su tamaño, pues se ha comprobado que no hay norma alguna que obligue a la aparición de ejemplos en todas las entradas y que ni los diccionarios lingüísticos ni los especializados son sistemáticos en la inclusión de ejemplos, en unas entradas figuran y en otras, no. En el Vocabulario se ha seguido la manera de proceder habitual en terminografía y se ha considerado obligada la presencia de citas en todos los artículos. El inconveniente mayor ha sido decidir si cada acepción debía contener una cita o, si por el contrario, una cita única servía para documentar todo el artículo, y, aunque la idea inicial fue la de documentar cada acepción y subacepción, muy pronto se comprobó que la inclusión de estos textos para dar cuenta del término en cada uno de sus sentidos aumentaba considerablemente el tamaño de la obra y, en la mayoría de las ocasiones, no aportaba ninguna información relevante respecto de la ya facilitada en la definición y en la cita adjuntada. Por ello cada entrada se acompaña de una única cita, que muestre el sentido general del término, independientemente del número de acepciones y de subentradas que contenga el artículo lexicográfico. Las citas incluidas en el ítem acondroplásico en DEA y en el Vocabulario ilustran lo mencionado en este párrafo:

TABLA 2

Citas

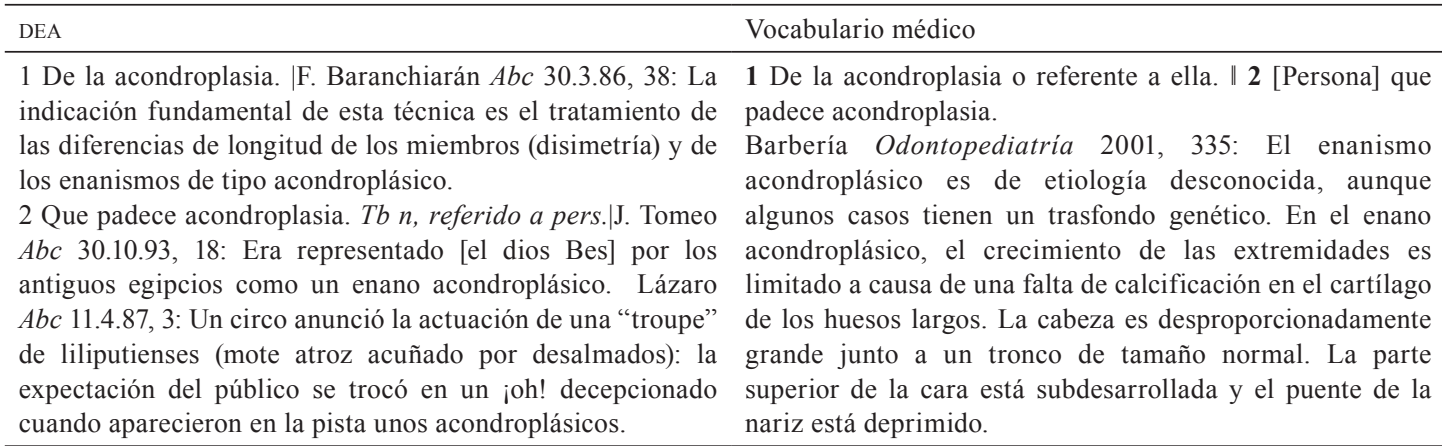


Se comprueba, pues, que se han buscado citas con el suficiente peso semántico, como para que se desprenda el sentido general del lema, sin necesidad de aportar ejemplos de uso de cada uno de los sentidos, pues la información proporcionada sería redundante en la mayoría de los casos e irrelevante.

En relación directa con el número de ejemplos que deben figurar en una entrada se encuentra el tamaño de la cita. En este Vocabulario se ha dado gran importancia al tamaño de la cita, pues no sólo se han buscado citas que completen la definición o que muestren el término en un contexto real, sino que debían cumplir una serie de requisitos diferentes, en muchos casos, a los que contemplan los diccionarios generales de lengua, como son: a) proporcionar definiciones encubiertas, siempre que ha sido posible y ello con la intención de corroborar el sentido del definido, pues algunas definiciones proporcionadas en los diccionarios de uso no son precisas y otras son incorrectas; b) incluir información enciclopédica que ayude a la comprensión; c) ayudar en la producción de mensajes; d) demostrar que los datos de la definición son fidedignos.

Buscar citas que cumplieran estos requisitos ha sido una ardua tarea, debido a la dificultad de documentación de muchas voces obsoletas, que solo se incluyen en obras lexicográficas. Por ello, el tamaño de las citas varía considerablemente, desde aquellas de tamaño menor, que constan de entre 10 y 30 palabras (cerasiote, abirritar, docimasiología), donde evidentemente no pueden cumplirse las funciones mencionadas, hasta aquellas de más de 90 palabras (abdomen agudo, eclampsia, electrochoque, ictiosis) e incluso de 100 (idiocia, flebitis, esfigmograma) donde se muestra que la cita cumple todas las funciones mencionadas en su totalidad. Véanse, a modo de ejemplo las citas de los lemas ictiosis o idiocia:

ictiosis [...] La ictiosis, una enfermedad dermatológica caracterizada por la descamación de la piel y por el aspecto sucio que ésta presenta (es más un problema estético que de salud), carece por ahora de un tratamiento farmacológico eficaz, pero podría tenerlo si se confirma el éxito obtenido con una sustancia antioxidante bien conocida, la $\mathrm{N}$-acetilcisteína, ... Los dermatólogos ... probaron inicialmente el fármaco en cultivos de células de la piel y después lo aplicaron en forma de crema en uno de los brazos de una enferma con ictiosis; al cabo de cinco semanas, advirtieron una "mejoría excepcional".

idiocia [...] J. E. Wiesner Discapacidad y capacidad intelectual 2004, 70: Un CI [Coeficiente Intelectual] de 25 a 39 señala imbecilidad, el niño se encuentra entre los severamente retrasados. Un CI de 24 o menos - el más bajo posible- significa idiocia y es muy difícil de cuantificar porque a los idiotas es muy arduo o imposible aplicarles las pruebas de inteligencia, son los retrasados profundos. Severos y profundos ocupan un extremo de la escala del histograma del CI. En el otro extremo de la escala intelectual están los superdotados. A partir de la inteligencia alta (CI entre 120 y 129) que se cita solo como referencia porque la inteligencia superior solo comienza con un CI de 130.

\section{Bibliografía}

Ahumada, Ignacio. 1989. Aspectos de lexicografía teórica. Aplicaciones al DRAE. Granada: Universidad de Granada.

Bosque, Ignacio. 1982. Sobre la teoría de la definición lexicográfica. Verba, 9: 105-123.

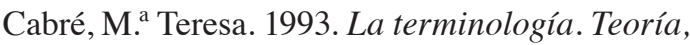
metodología, aplicaciones. Barcelona: Antártida/Empúries.

Casares, Julio. 1950. Dificultades que presenta la separación de acepciones. En Introducción a la lexicografía moderna. Madrid: CSIC, pp. 58-63.

Castro Ramos, Luciana. 1996. Notas sobre la definición en la tradición lexicográfica española: una lanza por el 'Diccionario de autoridades'. Acerca de la definición de los sustantivos que indican acción y resultado. En Actas del III Congreso 
Internacional de Historia de la lengua española. Madrid: Arco Libros, pp. 1219-1231.

Maldonado, Concepción (dir.). 2004. Clave. Diccionario de uso del español actual, 7. ed. Madrid: SM.

Collignon, Lucien y Michel Glatigny. 1978. Les dictionnaires. Initiation à la lexicographie, París: CEDIC.

Seco, Manuel, Olivia Andrés, y Gabino Ramos. 1999. Diccionario del español actual, Madrid: Aguilar.

Real Academia Española. 2001. Diccionario de la lengua española [versión electrónica], 22. ${ }^{\text {a }}$ ed. Madrid: Espasa Calpe.

Drysdale, Patrick D. 1987. The role of examples in English learner's dictionay. En A. P. Cowie (ed.) The Dictionary and the Language Learner, Papers form the EURALEX Seminar at the University of Leeds, 1-3 April 1985. Tübingen: Niemeyer (Lexicographica Series Maior 17), pp. 213-223.

Gutiérrez Cuadrado, Juan (dir.). 1996. Diccionario Salamanca de la lengua española. Madrid: Santillana.

Moliner, María. 2007. Diccionario de uso del español. Madrid: Gredos.

Fernández Sevilla, Julio. 1974. Problemas de lexicografía actual. Bogotá: Instituto Caro y Cuervo.

Haensch, Günther et al. 1982. La lexicografía. Madrid: Gredos.

Hernández, Humberto. 1994. Diccionarios enciclopédicos. En Humberto Hernández (coord.): Aspectos de lexicografía contemporánea. Barcelona: Bibliograf, pp. 61-69.

Hurtado de Mendoza, Manuel. 1840. Vocabulario médico-quirúrgico; o diccionario de Medicina y cirugía. Madrid: Boix Editor.

Landau, Sidney. 1984. Dictionaries. The Art and Craft of Lexicography. Nueva York: Scribner Press.

Mederos, Humberto. 1994. A propósito de la definición lexicográfica. En Humberto Hernández (coord.). Aspectos de lexicografía contemporánea. Barcelona: Bibliograf, pp. 95-106.

Murube, Juan,Eduardo Murube y Blas Mompeán. 2002. ¿Por qué deben evitarse los términos nictalopía y hemeralopía? (I y II). En Archivos de la Sociedad Española de Oftalmología, (3-4). http://www.oftalmo. com/seo/2002/03mar02/12.htm y http:// www.oftalmo.com/seo/2002/04abr02/12. htm Consulta: 20 de abril de 2010.

Olaeta, Roberto; Cundín, Margarita. 2011. Vocabulario médico. Con todas las voces recogidas en los diccionarios de uso. Bilbao: Itxaropena.

Porto Dapena, José Álvaro. 2002. Manual de técnica lexicográfica. Madrid: Arco Libros.

Rey-Debove, Josette. 1967. La definition lexicographique: bases d'une typologie formelle. En Travaux de linguistique et de literature, 8, 113-129.

1970. Le domaine du dictionnaire. En Langages: Didier/Larousse, 19, 3-34. 
1971. Étude linguistique et sémiotique des dictionnaires français contemporains. The Hague/Paris: Mouton.

Romero, Pilar. s.f.. "La RAE cambiará la definición de autismo". Ser padres http:// www.serpadres.es/salud/salud/la-raecambiara-la-definicion-de-autismo.html Consulta: 23 de julio de 2012)

Rondeau, Guy. 1983. Introduction à la terminologie. Chicoutimi (Quebec): Gaëtan Morin.

Seco, Manuel. 1987a. "Problemas formales de la definición". En Estudios de lexicografía española. Madrid: Paraninfo, 15-34.
. 1987b. El primer diccionario sincrónico del español. En Estudios de lexicografía española, Madrid: Paraninfo, 221-235.

Ullmann, Stephen. 1962. Semántica.Introducción a la ciencia del significado. Madrid: Aguilar, 1978.

Battaner, Paz (dir.). 2003. Diccionario de uso del español de América y España [versión electrónica]. Barcelona: Bibliograf.

Zgusta, Ladislav. 1971. Manual of Lexicographie. Praga-La Haya-París: Academia Mouton.

APÉNDICE 1

Vocablos con marca med no incluidos en el vocabulario médico

\begin{tabular}{|c|c|}
\hline \multicolumn{2}{|l|}{ DEA 1. EDICIÓN } \\
\hline VOCABLOS NO DETECTADOS & DEFINICIÓN \\
\hline aceptar $t r$ & Recibir [un órgano o tejido trasplantado] sin manifestar rechazo. \\
\hline actínico-ca adj & Causado por radiaciones actínicas. \\
\hline actinobacilosis $f$ & Enfermedad causada por especies del gén. Actinobacillus. \\
\hline aerosólico -ca adj & De(1) aerosol. \\
\hline aerosolterapia $f$ & Tratamiento terapéutico con aerosoles. \\
\hline aglutina $f$ & Aglutinina. \\
\hline aglutinógeno -na adj & Que estimula la producción de aglutinina. $T b n \mathrm{~m}$. \\
\hline aglutinoscopio $m$ & Aparato que sirve para observar la reacción de aglutinación. \\
\hline alergología $f$ & Especialidad que estudia las enfermedades alérgicas. \\
\hline alergólogo -ga adj & Especialista en alergología. \\
\hline $\operatorname{algidez} f$ & Estado patológico de frialdad corporal. \\
\hline amigdalectomía $f$ & Extirpación de las amígdalas. \\
\hline amiloide adj & $\begin{array}{l}\text { (Quim y Med) [Sustancia] proteica de naturaleza o aspecto de almidón. Frec } n \text { m, } \\
\text { esp designando la que se deposita en los tejidos de ciertos organos en determinadas } \\
\text { enfermedades. } 2 \text { (Quim y Med) Relativo a la sustancia amiloide [1]. }\end{array}$ \\
\hline anaplasmosis $f$ & Infección causada por microorganismos del gén. Anaplasma. \\
\hline anatomopatológico -ca $a d j$ & De (la) anatomía patológica. \\
\hline anergia $f$ & Falta de energía. \\
\hline angina pectoris $f$ & Angina de pecho. \\
\hline angiocolitis $f$ & Inflamación de los conductos biliares. \\
\hline
\end{tabular}




\begin{tabular}{|c|c|}
\hline angiogénesis $f$ & Formación o desarrollo de los vasos sanguíneos. \\
\hline angiografía $f$ & Radiografía de los vasos sanguíneos. \\
\hline angiográfico $-\mathrm{ca}$ adj & De (la) angiografía o de su objeto. \\
\hline ante partum loc adv & Antes del parto. \\
\hline antiberibérico -ca adj & Que actúa contra el beri-beri. \\
\hline aortografía $f$ & Radiografía de la aorta. \\
\hline areata $a d j$ & [Alopecia] rápida y completa en placas debida a trastornos de nutrición. \\
\hline ataráctico - ca adj & (Fil. o Med) Ataráxico. \\
\hline alálico -ca adj & (Med o lit.) De la alalia o que la implica. 2. (Med o lit.) Álalo. $T b n$. \\
\hline bacilar adj & (Biol y Med) $1 \mathrm{De}(1)$ bacilo o de (los) bacilos. 2 Que se produce mediante bacilos. \\
\hline bacilo $m$ & (Biol y Med) Bacteria en forma de bastoncillo. \\
\hline biosensor $m$ & $\begin{array}{l}\text { (Med y Biol) Sensor constituido por un chip electrónico unido a moléculas vivas, } \\
\text { que sirve para detectar la presencia de determinados fenómenos o sustancias en un } \\
\text { cuerpo vivo. }\end{array}$ \\
\hline citológico - ca adj & (Biol y Med) De la citologia o de su objeto. \\
\hline colibacilo $m$ & $\begin{array}{l}\text { (Biol y Med) Bacilo que habita en el intestino del hombre y de algunos animales, } \\
\text { patógeno en muchas ocasiones (Escherichia coli). }\end{array}$ \\
\hline colibacteria $f$ & (Biol y Med) Colibacilo. \\
\hline coliforme $a d j$ & (Biol y Med) Semejante al colibacilo. $T b \mathrm{n} m$, referido a bacilo. \\
\hline colinérgico-ca adj & (Biol y Med) Estimulado o transmitido por la acetilcolina. \\
\hline colónico - ca adj & (Anat y Med) De(l) colon. \\
\hline coprofagia $f$ & (lit o Med) Ingestión de excrementos. Tb fig. \\
\hline coprófago - ga adj & (lit o Med) Que ingiere excrementos. $T b n$, referido a pers. $T b$ fig. \\
\hline coprofilia $f$ & (lit o Med) Interés patológico por los excrementos. \\
\hline coprófilo -la adj & $\begin{array}{l}\text { (lit o Med) De (la) coprofilia. } 2 \text { (lit o Med) Que padece coprofilia. Tb } n \text {, referido a } \\
\text { pers. }\end{array}$ \\
\hline coprolalia $f$ & $\begin{array}{l}\text { (lit o Med) Tendencia patológica a decir obscenidades, esp. referidas a los } \\
\text { excrementos. }\end{array}$ \\
\hline cretinismo $m$ & $\begin{array}{l}\text { (Med) Enfermedad congénita debida a disfunción o ausencia del tiroides, y } \\
\text { caracterizada por la detención del desarrollo físico y mental y por deformidades } \\
\text { múltiples. }\end{array}$ \\
\hline dehiscente $a d j$ & (Bot y Med) Que se abre espontáneamente. \\
\hline denudación $f$ & (Med y Geol) Acción de denudar. \\
\hline denudar $t r$ & (Med y Geol) Privar [a algo (cd)] de su cubierta natural. \\
\hline dilacerar $t r$ & (lit o Med) Desgarrar [a una pers. o animal, o una parte de su cuerpo]. $\mathrm{Tb} \mathrm{pr}$. \\
\hline dislacerar $t r$ & (lit o Med) Dilacerar o desgarrar. $\mathrm{Tb} p r$. \\
\hline distal adj & (Anat o Med) Alejado del centro, de la línea media o del punto de origen. \\
\hline $\begin{array}{l}\text { dopa (acronimo; tb con la grafia } \\
\text { dopa) } f\end{array}$ & $\begin{array}{l}\text { (Quím y Med) Sustancia precursora de la dopamina, que contribuye a la síntesis de la } \\
\text { melanina y se utiliza en el tratamiento de la enfermedad de Parkinson. }\end{array}$ \\
\hline $\begin{array}{l}\text { ecodoppler ( } t \text { con la grafía } \\
\text { eco-dopler) } m\end{array}$ & $\begin{array}{l}\text { (Med) Técnica para determinar la velocidad de la sangre mediante el uso de } \\
\text { ultrasonidos. }\end{array}$ \\
\hline electrología $f$ & (Fis y Med) Estudio de los fenomenos eléctricos y de otros relacionados con ellos. \\
\hline emasculación $f$ & (lit o Med) Acción de emascular. \\
\hline emascular $t r$ & (lit o Med) Castrar [a alguien], o extirparle] los órganos de la generación. \\
\hline
\end{tabular}




\begin{tabular}{|c|c|}
\hline esclerotización $f$ & (Med o lit) Acción de esclerotizar-(se). \\
\hline esclerotizante $a d j$ & (Med o lit) Que esclerotiza. \\
\hline esclerotizar $t r$ & (Med o lit) Causar esclerosis [en alguien o algo $(\mathrm{cd})]$. \\
\hline esprúe (tb esprue) $m$ o $f$ & (Med) Enfermedad digestiva caracterizada esp. por malabsorción. \\
\hline esquinancia $f$ & (Med, hoy raro) Angina. \\
\hline estafilocócico -ca adj & (Biol y Med) De (los) estafilococos, o producido por ellos. \\
\hline explorador adj & (Med) [Utensilio] que sirve para explorar [3]. $\mathrm{Tb} n \mathrm{~m}$. \\
\hline feocromocitoma $m$ & (Med) Tumor de la médula suprarrenal. \\
\hline feticidio $m$ & (Med o Der) Acción de dar muerte a un feto. \\
\hline filaria $f$ & $\begin{array}{l}\text { (Zool y Med) Nematodo parásito propio de climas tropicales, que causa diversas } \\
\text { enfermedades (gén. Filaría). A veces designa dichas enfermedades. }\end{array}$ \\
\hline helminto $m$ & (Zool y Med) Gusano parasito del hombre y de los animales. \\
\hline hiperbaro -ra adj & (Fis y Med) Hiperbárico. \\
\hline $\operatorname{idiosincrasia~} f$ & $\begin{array}{l}2 \text { (Med) Sensibilidad anormal e individual a un medicamento, un alimento u otro } \\
\text { agente. }\end{array}$ \\
\hline infracción $f$ & 2 (Med) Fractura incompleta de un hueso. \\
\hline inmunizador -ra adj & (Med) Que inmuniza. \\
\hline licor $m$ & 2 (Med o lit) Sustancia liquida. Frec referido al semen. \\
\hline ligamentario -ria adj & (Med) De(1) ligamento. \\
\hline masoterapia $f$ & Med Tratamiento terapéutico mediante masaje. \\
\hline mecánico -ca adj & 4 Med [Asfixia] causada por obstrucción interna o externa de las vías respiratorias. \\
\hline metabolimetría $f$ & (Med) Medición del metabolismo basal. \\
\hline metabolímetro $m$ & (Med) Aparato para medir el metabolismo basal. \\
\hline miasténico -ca adj & (Med) De (la) miastenia. \\
\hline microencefalia $f$ & (Med) Microcefalia. \\
\hline mielosis $f$ & (Med) Afección o alteración de la médula ósea o espinal. \\
\hline migrañoso -sa adj & (Med) De (la) migraña. 2 (Med) Que padece migraña. $T b$, referido a pers. \\
\hline motilidad $f$ & (Med) Movilidad. \\
\hline mucociliar adj & (Med) De la mucosa y los cilios de las vías respiratorias. \\
\hline mucoide adj & (Med) Semejante al mucus. \\
\hline mucolítico -ca adj & (Med) Que disuelve la mucosidad. $T b n$ m, referido a producto. \\
\hline neonatal adj & (Med) De(l) neonato. \\
\hline neonato - ta adj & (Med o lit) Recién nacido. Frec $n$. \\
\hline neurósico -ca adj & $(M e d)$ Neurótico [1]. \\
\hline neutrofilia $f$ & (Med) Aumento del número de leucocitos neutrófilos en la sangre. \\
\hline obesidad $f$ & (lit o Med) Cualidad de obeso. \\
\hline obeso -sa adj & (lit o Med) [Pers.] excesivamente gruesa. Tb fig, referido a cosa. \\
\hline objetivar intr $\mathrm{pr}$ & B 2 (Med) Manifestarse o exteriorizarse [una cosa]. \\
\hline oleato $m$ & $\begin{array}{l}\text { (Quím y Med) Sal del acido oleico, usada en medicina como disolvente de determina- } \\
\text { das sustancias o medicamentos. }\end{array}$ \\
\hline organicista adj & (Filos o Med) De(l) organicismo. \\
\hline ortofonía $f$ & (Med y Fon) Corrección de los defectos de la voz y de la pronunciación. \\
\hline ortofónico -ca adj & (Med y Fon) De (la) ortofonía. \\
\hline
\end{tabular}




\begin{tabular}{|c|c|}
\hline ortofonista $m$ y $f$ & (Med y Fon) Especialista en ortofonía. \\
\hline pacemaker $m$ & (Med) Marcapasos. \\
\hline paliativo -va adj & b) (Med) Que alivia pero no cura. $T b n$ m, referido a medicamento o remedio. \\
\hline paregórico -ca adj & (Med) [Elixir] calmante que contiene extracto de opio. \\
\hline pédico -ca adj & (Med) De(l) pie. \\
\hline $\operatorname{pian} m$ & $\begin{array}{l}\text { (Med) Enfermedad contagiosa, propia de países cálidos, caracterizada por erupciones } \\
\text { en la cara, manos, pies y regiones genitales. }\end{array}$ \\
\hline pilonidal adj & $(\mathrm{Med})$ [Fístula o quiste] que tiene pelos en su interior. \\
\hline placa $f$ & 8 (Med) Lesión de superficie bien delimitada. \\
\hline planchuela $f$ & $\begin{array}{l}\text { (Med, hist) Conjunto plano de hilas poco apretadas, usado en la curación de heridas } \\
\text { o llagas extensas. }\end{array}$ \\
\hline plástico -ca adj & $\begin{array}{l}4 \text { c) (Med) [Cirugía o cirujano] que se ocupa de tratamientos de reconstrucción o } \\
\text { estéticos. }\end{array}$ \\
\hline predisponer $t r$ & 2 (Med) Predisponer [1] al organismo [para una enfermedad o una alteración $(c d)]$. \\
\hline proximal adj & (Anat o Med) Próximo al centro, a la línea media o al punto de origen. \\
\hline puérpera $f$ & (lit o Med) Mujer recién parida. \\
\hline pulsógrafo $m$ & (Med, raro) Instrumento que registra el pulso arterial. \\
\hline pulsómetro $m$ & (Med) 1 Aparato para medir el pulso arterial. \\
\hline rehidratar $t r$ & (E, esp Med) Reponer [en un cuerpo, organismo o tejido $(c d)$ ] el agua perdida. $T b$ abs. \\
\hline repleción $f$ & (Med o lit) Cualidad de repleto. \\
\hline resorcina $f$ & $\begin{array}{l}\text { (Quím o Med) Fenol utilizado como antiséptico y para la preparación de determina- } \\
\text { dos colorantes. }\end{array}$ \\
\hline retractar $t r$ & (Med) Retraerse [4]. \\
\hline rigor mortis $m$ & (Med) Rigidez cadavérica. Tb (lit) fig, fuera del ambito tecn. \\
\hline saburroso -sa $a d j$ & $\begin{array}{l}\text { (lit o Med) Saburral. } 2 \text { (lit o Med) [Diente] que tiene sarro. } 3 \text { (lit o Med) De(l) sarro de } \\
\text { los dientes. }\end{array}$ \\
\hline salva de extrasístoles $f$ & (Med) Extrasistoles que se producen en sucesión rápida. \\
\hline sindactilia $f$ & (.Anat y Med) Hecho de tener los dedos soldados entre sí. \\
\hline sindáctilo -la adj & $\begin{array}{l}\text { (Anat y Med) Que tiene dos o más dedos soldados entre sí. Se opone a deodáctilo. } T b \\
n: m \text { y freferido a pers; } m \text {, referido a ave. }\end{array}$ \\
\hline $\begin{array}{l}\text { stress (ing; pronunc corriente, / } \\
\text { estres/; pl, invar o es) } m\end{array}$ & $(\mathrm{Med})$ Estrés. \\
\hline stressante $a d j$ & (Med) Estresante. \\
\hline surmenage $m$ & (Med, hoy raro) Estado depresivo causado por agotamiento físico o psíquico. \\
\hline susceptible adj & $\begin{array}{l}1 \text { b) (Med y Vet) Que tiene cierta predisposición [a una enfermedad (compl de)]. Tb } \\
\text { sin compl. }\end{array}$ \\
\hline tarugo $m$ & $\begin{array}{l}3 \text { (argot Med) Comisión pagada por un laboratorio farmacéutico por recetar sus } \\
\text { productos. }\end{array}$ \\
\hline tebaico - ca adj & (Med) [Extracto] acuoso de opio. \\
\hline tebaína $f$ & (Med) Alcaloide tóxico extraído del opio. \\
\hline tocoginecología $f$ & (Med) Parte de la medicina que comprende la tocología y la ginecología. \\
\hline trimetadiona $f$ & Med) Tridiona. \\
\hline vacinostilo $m$ & (Med) Pluma metálica muy puntiaguda que se emplea para vacunar. \\
\hline vesicular $t r$ & (Anat o Med) De (la) vesícula o de (las) vesículas. \\
\hline vesiculoso -sa $a d j$ & (Anat o Med) De las vesículas, esp [2], o que las implica. \\
\hline
\end{tabular}


c) $\sim$ en tabla, $o \sim$ de madera.

\begin{tabular}{ll}
\hline vigil $a d j$ & $($ Med $)$ De (la) vigilia. \\
\hline viriásico - ca $a d j$ & $($ Med $)$ Vírico o virásico. \\
\hline viriasis $f$ & Afección por virus [1]. \\
\hline
\end{tabular}

\section{APÉNDICE II}

Unidades pluriverbales

\begin{tabular}{|c|c|c|}
\hline agua & $\sim$ angélica. & Purgante suave con crémor tártaro (\| bitartrato potásico) y maná (\| líquido azucarado). \\
\hline aguardiente. & alemán. & $\begin{array}{l}\text { Purgante fuerte compuesto de jalapa (\| planta trepadora con fuerte acción purgante), } \\
\text { escamonea (\| gomorresina medicinal muy purgante) y turbit (\| planta trepadora } \\
\text { empleada como purgante drástico). }\end{array}$ \\
\hline árbol & $\sim$ respiratorio. & Estructura anatómica formada por la ramificación de bronquios y bronquiolos. \\
\hline asta & $\sim$ s de la médula. & $\begin{array}{l}\text { Apéndice o prolongación de la sustancia gris en el seno de la sustancia blanca de la médula } \\
\text { espinal, de forma similar a un cuerno. }\end{array}$ \\
\hline botón & $\sim$ de fuego. & $\begin{array}{l}\text { Cauterización superficial con un hierro candente o con el termocauterio ( } \| \text { cauterio } \\
\text { hueco que se mantiene candente por electricidad). Se empleaba como revulsivo. }\end{array}$ \\
\hline claudicación & $\sim$ intermitente. & $\begin{array}{l}\text { Entumecimiento doloroso y rigidez de las piernas que sobreviene después de algunos } \\
\text { instantes de marcha y que se alivian con el reposo, causada por la mala circulación. }\end{array}$ \\
\hline clavo. & $\sim$ pasado. & $\begin{array}{l}\text { En veterinaria, tumor duro y calloso que sale a las caballerías en uno o en los dos lados } \\
\text { de las cuartillas (\| parte de la pata inmediatamente anterior al nacimiento del casco). }\end{array}$ \\
\hline cordón & $\sim$ sanitario. & $\begin{array}{l}\text { Conjunto de medidas de prevención y control que se toman para evitar la propagación } \\
\text { de una enfermedad contagiosa, de una epidemia o de una plaga. }\end{array}$ \\
\hline espectro & $\sim$ antibiótico. & $\begin{array}{l}\text { Conjunto de microorganismos sobre los que un medicamento, especialmente un } \\
\text { antibiótico, es eficaz. }\end{array}$ \\
\hline fuego & $\begin{array}{l}\sim \text { pérsico. } \\
\sim \text { potencial. }\end{array}$ & $\begin{array}{l}\text { Nombre antiguo con que se designaba unas veces las enfermedades carbuncosas y otras } \\
\text { el ergotismo y la erisipela. } \\
\text { Virtud ígnea de minerales, plantas o piedras corrosivas. }\end{array}$ \\
\hline furor & $\sim$ uterino. & Ninfomanía o deseo sexual incontrolado en la mujer. \\
\hline hígado & $\begin{array}{l}\sim \text { de antimonio. } \\
\sim \text { de azufre. }\end{array}$ & $\begin{array}{l}\text { (desusado) Sustancia de color pardo oscuro, reluciente, resultante de la fusión en un } \\
\text { crisol de óxido y sulfuro de antimonio, usado, especialmente en polvo, como vermífugo } \\
\text { y purgante en la veterinaria. } \\
\text { (desusado) Sustancia resultante de la mezcla de } 100 \text { partes de azufre y } 200 \text { de carbonato } \\
\text { de potasa, usado en la composición de diversas pomadas y jabones, y en la preparación de } \\
\text { lociones y baños hidrosulfurados. }\end{array}$ \\
\hline moscas & $\sim$ S volantes. & $\begin{array}{l}\text { Manchas pequeñas, oscuras y móviles percibidas delante del campo visual por algún } \\
\text { defecto de la vista. }\end{array}$ \\
\hline pie & $\sim$ de atleta. & $\begin{array}{l}\text { Infección por hongos del género Trichophyton, que afecta a la piel que hay entre los } \\
\text { dedos de los pies o a la planta, caracterizada por enrojecimiento, picor, grietas o } \\
\text { escamación entre los dedos de los pies y ampollas o escamas en la planta. }\end{array}$ \\
\hline piedra & $\sim$ divina. & Mezcla de sulfato de cobre, nitrato potásico, alumbre y alcanfor, usado como colirio. \\
\hline punto & $\begin{array}{l}\sim \text { de costado. } \\
\sim \text { neurálgico. }\end{array}$ & $\begin{array}{l}\text { Dolor agudo y punzante en el lado izquierdo, junto al corazón. } \\
\text { Lugar de encuentro de un grupo de nervios. }\end{array}$ \\
\hline risa & $\sim$ sardónica. & $\begin{array}{l}\text { Contracción convulsiva de los músculos faciales, con los dientes apretados que semeja } \\
\text { la risa, propio de algunas enfermedades, como el tétanos. }\end{array}$ \\
\hline tabardillo & $\sim$ pintado. & Tifus exantemático. \\
\hline
\end{tabular}




\begin{tabular}{lll}
\hline vegetación & $\sim$ adenoidea. & $\begin{array}{l}\text { Alteración o hipertrofia del tejido linfoideo que rodea la nasofaringe y la orofaringe } \\
\text { de los niños. }\end{array}$ \\
\hline ventosa & $\sim$ escarificada, & $\begin{array}{l}\text { Ventosa que se aplica sobre una superficie en la que se ha practicado incisiones o } \\
\text { sajaduras en el sitio limitado al círculo de la ventosa. }\end{array}$ \\
& $\sim$ seca. & La que se aplica sobre una superficie sin producir evacuación de sangre al exterior. \\
\hline
\end{tabular}

\section{APÉNDICE III}

Consignación de la categoría gramatical de las locuciones

\begin{tabular}{|c|c|c|c|}
\hline$f$. & catarata & $\begin{array}{l}\text { loc. vbal. } \\
\text { loc. vbal. }\end{array}$ & $\begin{array}{l}\text { batir la catarata } \\
\text { extraer la catarata }\end{array}$ \\
\hline$m$. & choque & loc. adj. & de choque \\
\hline$m$. & consentimiento & $l o c . a d v$ & por consentimiento \\
\hline$m$. & Colles & loc. adj. & de Colles \\
\hline$m$. & corazón & $l o c . a d v$ & a corazón abierto \\
\hline$m$ & disco & loc. adj. & de disco \\
\hline$f$. & granulación & loc. adj. & de granulación \\
\hline$f$. & gota & loc. $a d v$ & gota a gota \\
\hline$f$. & herida & loc. vbal. & manifestar la herida \\
\hline$f$. & hernia & loc. adj. & hernia de hiato \\
\hline$f$. & intención & loc. vbal. & curar de primera intención \\
\hline$m$. & martillo & loc. adj. & en martillo \\
\hline adj. & resistente & loc. vbal. & hacerse resistente \\
\hline$f$ & sábana & loc. adj. & en sábana \\
\hline$f$. & sangre & frase hecha & tomar la sangre \\
\hline$f$. & sustancia & loc. adv. & en sustancia \\
\hline$f$. & vena & frase hecha & descabezarse una vena \\
\hline$m$. & Wasermann & loc. adj. & de Wasermann \\
\hline
\end{tabular}

\section{APÉNDICE IV}

Adición de nuevas acepciones

\begin{tabular}{|c|c|c|}
\hline Término & Diccionarios de uso & Vocabulario \\
\hline Síntesis & $\begin{array}{l}\text { Cir. Operación que consiste en unir los fragmentos } \\
\text { de una estructura lesionada (DUE). } \\
5 \text { MED. Operación de cirugía que consiste en unir } \\
\text { los fragmentos de una estructura lesionada (DSLE). }\end{array}$ & $\begin{array}{l}1 \text { Intervención quirúrgica consistente en la } \\
\text { introducción de un clavo o pieza metálica } \\
\text { alargada para unir fragmentos de una parte } \\
\text { lesionada. ॥ } 2 \text { Elaboración de un compuesto } \\
\text { químico formado por la combinación de } \\
\text { varios elementos. }\end{array}$ \\
\hline Tanatofilia & $\begin{array}{l}\text { Gusto exagerado por todo lo que rodea al fenómeno } \\
\text { de la muerte (DEA). }\end{array}$ & $\begin{array}{l}1 \text { Tendencia al suicidio o deseo enfermizo de } \\
\text { morir } \mathbf{2} \text { Atracción por las cosas fúnebres y lo } \\
\text { que rodea a la muerte. }\end{array}$ \\
\hline
\end{tabular}




\begin{tabular}{ll}
\hline Titilación & $\begin{array}{l}\text { (lit. o Med.) Acción de titilar. Tb su efecto (DEA, } \\
\text { DUE, DRAE01). }\end{array}$ \\
\hline Titilar & $\begin{array}{l}\text { Rozar o estimular ligeramente (las mucosas nasales } \\
\text { o el velo del paladar], para producir el estornudo o } \\
\text { el vómito (DEA). }\end{array}$ \\
\hline \multirow{7}{*}{ Toracoplastia } & $\begin{array}{l}\text { Operación de resección de algunas costillas, } \\
\text { practicada en algunos casos de tuberculosis } \\
\text { pulmonar con el fin de disminuir la capacidad de } \\
\text { un hemitórax y facilitar el colapso pulmonar (DEA). }\end{array}$ \\
& $\begin{array}{l}\text { y las condiciones funcionales de la cavidad torácica } \\
\text { por resección de varias costillas (DUE). }\end{array}$ \\
& $\begin{array}{l}\text { Med. Resección de una o varias costillas para } \\
\text { modificar las condiciones funcionales de la cavidad } \\
\text { torácica (DRAE01). }\end{array}$ \\
\hline Transfusor & 2 n. Med. Transfusionista (DUE). \\
\hline Transducción & $\begin{array}{l}\text { MED. Transformación de una vivencia psíquica en } \\
\text { otra psicosomática: Muchas jaquecas pueden ser } \\
\text { resultado de un fenómeno de transducción (DSLE). }\end{array}$ \\
\hline
\end{tabular}

1 Hormigueo, cosquilleo o picazón suave.ı 2 Estimulación de una parte del organismo para conseguir una respuesta refleja.

1 Producir o causar sensación de hormigueo, cosquilleo o picazón suave.\| 2 Estimular una parte del organismo para producir una respuesta refleja.

1 Nombre genérico para la cirugía plástica del tórax.I 2 Intervención quirúrgica consistente en la resección o extirpación de una o varias costillas, a causa de un tumor o de lesiones tuberculosas.

1 Aparato utilizado para practicar una transfusión $\mathbf{2}$ Transfusionista.

1 Mecanismo de transmisión de marcadores genéticos de una cepa bacteriana a otra. ॥ 2 Transformación de una forma de energía en otra o de una sensación psíquica en otra psicosomática.

1 Malformación congénita que consiste en el desplazamiento de un órgano o víscera al lado opuesto.» 2 Intervención quirúrgica que consiste en cambiar un tejido u órgano al lado opuesto. || 3 Intervención quirúrgica que consiste en cambiar un tejido de un lugar a otro sin cortarlo completamente de su lugar de origen hasta que se haya fijado en su nueva localización.

\begin{tabular}{|c|c|c|}
\hline Trauma & Traumatismo (DEA, DSLE). & $\begin{array}{l}1 \text { Daño psicológico o emocional, debido a un } \\
\text { choque emocional intensol } \mathbf{2} \text { Traumatismo. }\end{array}$ \\
\hline Trigémino & $\begin{array}{l}1 \text { adj. Med. Se aplica a los *hermanos nacidos en un } \\
\text { parto de tres (DUE). }\end{array}$ & $\begin{array}{l}\mathbf{1} \text { [Parto] de trillizos. । } \mathbf{2} \text { [Persona] nacida en } \\
\text { un parto de trillizos. }\end{array}$ \\
\hline Urograma & Imagen radiográfica de las vías urinarias (DEA). & $\begin{array}{l}1 \text { Urografía. ॥ } 2 \text { Imagen radiológica del } \\
\text { aparato urinario o de una parte de él, obtenida } \\
\text { mediante urografía. }\end{array}$ \\
\hline Urolitiasis & $\begin{array}{l}\text { Formación de cálculos o concreciones en las vías } \\
\text { urinarias (DEA). }\end{array}$ & $\begin{array}{l}1 \text { Enfermedad debida a la presencia de } \\
\text { piedras o cálculos en la pelvis renal o en } \\
\text { cualquier parte de la vía urinaria (vejiga, } \\
\text { uréter, uretra). I } 2 \text { Proceso de formación de } \\
\text { piedras o cálculos urinarios. }\end{array}$ \\
\hline Urticárico & Que padece urticaria. Tb n. (DEA). & Urticarial. \\
\hline Varicosidad & Variz. (DEA, DUE). & 1 Variz」 2 Alteración de carácter varicoso. \\
\hline
\end{tabular}




\begin{tabular}{|c|c|c|}
\hline \multirow{5}{*}{ Vegetación } & $\begin{array}{l}\text { Hipertrofia de las amígdalas faríngeas y nasales y } \\
\text { de los folículos linfáticos de la parte posterior de } \\
\text { las fosas nasales. Tb (Med) ES ADENOIDEAS (DEA). }\end{array}$ & \multirow{5}{*}{$\begin{array}{l}1 \text { Alteración o hipertrofia del tejido linfoideo } \\
\text { que rodea la nasofaringe y la orofaringe de } \\
\text { los niños. Adenoides.l } 2 \text { Formación anormal } \\
\text { de tejido o carnosidad que crece en la super- } \\
\text { ficie de las heridas, de algún órgano o en la } \\
\text { mucosa. }\end{array}$} \\
\hline & Med. VEGETACIONES adenoideas. & \\
\hline & $\begin{array}{l}\text { Hipertrofia de las amígdalas de la faringe, con car- } \\
\text { acteres de tumor blando (DUE). }\end{array}$ & \\
\hline & Med. Hipertrofia de las amígdalas faríngea y nasal & \\
\hline & $\begin{array}{l}\text { y, sobre todo, de los folículos linfáticos de la parte } \\
\text { posterior de las fosas nasales. U. } m \text {. en pl. (DRAE01). }\end{array}$ & \\
\hline
\end{tabular}

\section{APÉNDICE V}

Términos que complementan las definiciones

\begin{tabular}{|c|c|c|c|}
\hline LEMAS & $\begin{array}{l}\text { Términos no validados que } \\
\text { completan la definición }\end{array}$ & LEMAS & $\begin{array}{l}\text { Términos no validados que } \\
\text { completan la definición }\end{array}$ \\
\hline acetonemia & acetona & leucocitosis & leucocito \\
\hline addisoniano & enfermedad de addison & macular & mácula \\
\hline agua angélica & crémor tártaro / maná & maleolar & maléolo \\
\hline aguardiente alemán & jalapa / escamonea / turbit & medicina nuclear & radioisótopo \\
\hline alantoideo & alantoides & melanosis & melanina \\
\hline albuminuria & albumina & meningococo & diplococo \\
\hline alergénico & alergia & mesenteritis & mesenterio \\
\hline algolágnico & algolagnia & mesomorfo & mesodermo \\
\hline alqermes & quermes animal & metahemoglobinemia & metahemoglobina \\
\hline amebiano & amebas & mielinización & mielina \\
\hline amigdalitis & amígdalas & neumoencefalografía & ventrículo cerebral \\
\hline anatomofisiológico & fisiología & neumomediastino & mediastino \\
\hline anestesiología & anestésico & neuroanatómico & neuroanatomía \\
\hline anexitis & anexos uterinos & opiáceo & opio \\
\hline anginoso & anginas & ortopeda & ortopedia \\
\hline anidación & útero & ortóptica & optometría \\
\hline anisakiasis & anisakis & osteoclastia & osteoclasto \\
\hline anisometropía & refracción & otorrino & otorrinolaringología \\
\hline anticolesterol & colesterol & PAS & micobacterias \\
\hline anticolinesterasa & colinesterasa & palestésico & palestesia \\
\hline aquilia & quilo & palo & quina \\
\hline artético & articulación & pancarditis & $\begin{array}{l}\text { pericardio / endocardio / mio- } \\
\text { cardio }\end{array}$ \\
\hline
\end{tabular}




\begin{tabular}{|c|c|c|c|}
\hline asistolia & sístole & pancreatitis & páncreas \\
\hline atropina & belladona & parasitario & parásito \\
\hline bagazosis & bagazo & pediátrico & pediatría \\
\hline benzolismo & benzol & penicilamina & quelante \\
\hline bronquiolitis & bronquiolo & pericarditis & pericardio \\
\hline bursina & alcaloide & pernicioso & megaloblasto \\
\hline cantaridina & cantárida & pigmentario & pigmento \\
\hline cardial & cardias & piloroplastia & píloro \\
\hline cardialgia & precordial & pinealoma & glándula pineal \\
\hline cetogénesis & cuerpos cetónicos & plaquetario & plaqueta \\
\hline clitoritomía & clítoris & plasmaféresis & plasma \\
\hline colibacilar & colibacilo & pleuritis & pleura \\
\hline comatoso & coma & poción & excipiente \\
\hline coprocultivo & patógeno & polinucleosis & leucocito \\
\hline coroiditis & coroides & poliomielitis & poliovirus \\
\hline coxigodinia & coxis & porfina & porfirina \\
\hline descerebelar & cerebelo & prediabetes & glicemia \\
\hline desfibrilación & fibrilación & prednisolona & corticosteroide \\
\hline desfibrinación & fibrina & prepuberal & pubertad \\
\hline diascordio & escordio & prostático & próstata \\
\hline dislipemia & lípido & pubarquía & pubertad \\
\hline distress & distress respiratorio & pulpitis & pulpa dental \\
\hline ectomorfo & ectodermo & queratoma & capa córnea \\
\hline emulsivo & emulsión & rádium & radio \\
\hline endocarditis & endocardio & refractometría & refracción \\
\hline endolaríngeo & laringe & retinitis & retina \\
\hline endomorfo & endodermo & retrovirus & $\mathrm{ARN} / \mathrm{ADN}$ \\
\hline endotelioma & endotelio & rinofaringitis & faringe \\
\hline endotraqueal & tráquea & rinoscopia & rinoscopio \\
\hline epididimitis & epidídimo & roentgenografía & radiografía \\
\hline epidural & duramadre & salipirina & salicitato \\
\hline epigastralgia & epigastrio & sifilográfico & sifilografía \\
\hline ergotismo & cornezuelo & simpaticotónico & simpaticotonía \\
\hline esofagitis & esófago & simpatina & noradrenalina \\
\hline espina bífida & meninges & sinoptóforo & visión binocular \\
\hline elplenectomía & bazo & sinovitis & membrana sinovial \\
\hline estapedectomía & estribo & sinusitis & senos prenasales \\
\hline estreptococia & estretococo & somestésico & somestesia \\
\hline eupepsia & pepsina & subcutáneamente & subcutáneo \\
\hline extradural & duramadre & suberosis & polvo de corcho \\
\hline
\end{tabular}




\begin{tabular}{|c|c|c|c|}
\hline extrapiramidal & vía piramidal & tendinitis & tendón \\
\hline exulceración & epidermis & tenífugo & tenia \\
\hline fenilcetonuria & fenilalanina & terapéutico & terapéutica \\
\hline fetal & feto & tiraje & epigastrio \\
\hline fibrinólisis & fibrina & tocoginecológico & tocoginecología \\
\hline filariasis & filarias & traqueítis & tráquea \\
\hline fimatosis & fimas & tricofítico & tricofitosis \\
\hline glioma & células gliales & tripanosomiasis & artrópodo \\
\hline granulocitosis & granulocitos & triquinado & triquina \\
\hline granulomatosis & vascularizado & troncular & trónculo \\
\hline hernia de hiato & diafragma & ureteritis & uréter \\
\hline hidrácida & amina & uretritis & uretra \\
\hline hidronefrosis & cáliz renal & urológico & urología \\
\hline hipocóndrico & hipocondrio & vacunal & vacuna \\
\hline hipomenorrea & miometrio & vainillismo & vainillina \\
\hline hipoprotrombinemia & protrombina & vasal & vaso \\
\hline hirudina & trombina & vasectomía & conductos deferentes \\
\hline histopatología & histología & verrugosidad & verruga \\
\hline \multirow[t]{2}{*}{ ionización } & ión & vólvulo & eje mesentérico \\
\hline & & vulviforme & vulva \\
\hline
\end{tabular}

\section{APÉNDICE VI}

Citas

\section{Artículo lexicográfico}

hipostenia $f$ Debilidad.

algidez $f . \|$ Frialdad del cuerpo, especialmente de las extremidades, como en el colapso, cólera, etcétera.

amétrope $a d j . / m . y f . \| 1[\mathrm{Ojo}]$ con error de refracción en la visión, en la que los hace luminosos procedentes del infinito no se enfocan sobre la retina. $\| 2$ [Persona] que padece ametropía.
Cita

Pommier Diccionario homeopático de urgencia 2002, 422: La hipostenia se caracteriza por la debilitación del funcionamiento de ciertos tejidos y órganos, especialmente de la infancia a la edad adulta. Se reconoce por su fatigabilidad física, con astenia progresiva (disminución de las fuerzas a medida que el día avanza), la necesidad de reposo y relajación; su concentración, ansiedad, depresión y su pesimismo.

Pommier Diccionario homeopático de urgencia 2002, 330-331: Intoxicaciones alimentarias por setas. Signos: incubación de aproximadamente 8 horas después de la comida, aunque puede prolongarse más. Al principio ardor de estómago, fuertes dolores abdominales, síndrome coleriforme (diarrea, sudores abundantes, sed intensa); estado general muy afectado; algidez (enfriamiento con sensación de frío), colapso (disminución rápida de la actividad cerebral), oliguria (disminución de la cantidad de orina).

Quevauvilliers Diccionario de enfermería: enciclopedia práctica 2004, 49: En el ojo normal o emétrope, un objeto situado en el infinito produce una imagen nítida sobre la retina. En el ojo amétrope, la imagen de un objeto situado en el infinito no se reproduce sobre la retina, por lo que su visión es borrosa. La agudeza visual no es satisfactoria, pero mejora con cristales correctores, al contrario de lo que ocurre en la ambliopía. Se habla entonces de trastornos de la refracción. 
friura (desusado) $f . \mid$ Lesión de la piel producida por el frío.

fronda (desusado) $f . \|$ Vendaje de cuatro cabos empleado en el tratamiento de fracturas y heridas, especialmente en la nariz y mandíbula.

fulguración $f \|$ Destrucción de un tejido mediante corriente eléctrica. $\| 2$ Efecto provocado por la acción de un rayo en el organismo.

respigón (desusado) m| Grieta que aparece en el pecho de la mujer durante la lactancia.
Marañón Manual de diagnóstico etiológico 1943, 80: La más importante de estas gangrenas es la del frío. Produce primero rubicundez, luego vesicación y, por fin, la gangrena. Su forma más banal es la escara formada sobre muchos sabañones que afectan principalmente a jóvenes con acrocianosis. Las friuras muy intensas, atmosféricas, pueden producir gangrena grave de las orejas, nariz, manos, pies; estas gangrenas aparecen con una cierta independencia de los síntomas generales del enfriamiento: temblor muscular, astenia, bostezos, somnolencia, convulsiones, muerte aparente.

González El practicante 1886, 147-148: Cuando una compresa es muy larga, y proporcionalmente muy estrecha, y está hendida en sus dos extremidades, dejando únicamente un espacio de algunos centímetros en el centro sin cortar, se llama fronda. ... Su uso por lo general es contentivo, y en su aplicación sirve para sujetar tópicos, o piezas de apósito sobre determinada parte, y para preservarlas de las influencias exteriores. Son muy útiles por su sencillez, por ser muy ligeras, dan poco calor al punto que se aplican, pero generalmente no contienen con mucha exactitud los objetos que cubren sí han de ser por algún tiempo sostenidos.

Perelló Trastornos del habla 2005, 471: Fulguración lingual. Esta lesión, producida alrededor de los 12 meses de edad, es relativamente frecuente por introducir la punta de la lengua en un enchufe eléctrico. Debido a la humedad se produce una descarga eléctrica que quema la punta de la lengua; a los pocos días al desprenderse la escara se producen serias hemorragias. Luego queda una pérdida de sustancia y una cicatriz que dificulta la articulación.

Diario de Madrid n. ${ }^{\circ} 170$ 1796, 685: Don Alfonso Peláez, dentista, ... vende unos polvos para blanquear la dentadura, y unas pezoneras de nueva invención para curar los respigones o grietas de los pechos, cuyos arbitrios y demás que en adelante pueda granjear a expensas de su desvelo y estudio, ofrece emplear en obsequio del público, asistiendo a los pobres sin interés alguno.

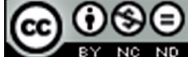

Este obra está bajo una licencia de Creative Commons

Reconocimiento-NoComercial-SinObraDerivada 4.0 Internacional. 